\title{
INFLUÊNCIA DO CAPITAL PSICOLÓGICO NA MOTIVAÇÃO PARA APRENDIZAGEM E AQUISIÇÃO DE CONHECIMENTOS
}

\author{
Vinícius Costa da Silva Zonatto ${ }^{1}$ \\ Júlia Ziliotto Zanotto 2 \\ Priscila Rodrigues da Silva ${ }^{3}$ \\ Larissa Degenhart 4 \\ Luiz Henrique Figueira Marquezan 5
}

- Artigo recebido em: 06/04/2020 -- Artigo aceito em: 18/05/2020 -- Segunda versão aceita em: 06/07/2020

\section{RESUMO}

A pesquisa analisa a influência do capital psicológico na motivação para aprendizagem e aquisição de conhecimentos de alunos de um curso de graduação presencial em Ciências Contábeis. Pesquisa descritiva foi realizada mediante levantamento com 235 alunos de uma IES e abordagem quantitativa, com modelagem de equações estruturais. Investigou-se três hipóteses, que versam sobre a influência direta do capital psicológico na motivação para aprendizagem (H1) e na aquisição de conhecimentos $(\mathrm{H} 2)$ e os efeitos mediadores da motivação para aprendizagem na relação entre capital psicológico e aquisição de conhecimentos (H3). Os resultados revelaram que o

1 Pós Doutor em Ciências Contábeis (UNISINOS), Doutor em Ciências Contábeis e Administração (FURB), Professor do Programa de Pós-Graduação em Ciências Contábeis da Universidade Federal de Santa Maria (PPGCC/UFSM), Endereço: Av. Roraima, $n^{\circ} 1000$, Cidade Universitária, CCSH, Prédio 74C, Sala 4345, $3^{\circ}$ Andar, Bairro Camobi, CEP: 97.105-900, Santa Maria/RS, Brasil. E-mail: viniciuszonatto@gmail.com

https://orcid.org/0000-0003-0823-6774

2 Bacharel em Ciências Contábeis (UFSM). Endereço: Av. Roraima, $n^{\circ}$ 1000, Cidade Universitária, CCSH, Prédio 74C, $3^{\circ}$ Andar, Bairro Camobi, CEP: 97.105-900, Santa Maria/RS, Brasil. E-mail: julia_zanotto@hotmail.com

https://orcid.org/0000-0002-5396-9291

3 Bacharel em Ciências Contábeis (UFSM). Endereço: Av. Roraima, $n^{\circ}$ 1000, Cidade Universitária, CCSH, Prédio 74C, $3^{\circ}$ Andar, Bairro Camobi, CEP: 97.105-900, Santa Maria/RS, Brasil. E-mail: priscila.rods@hotmail.com

https://orcid.org/0000-0003-4446-6446

${ }^{4}$ Doutora em Ciências Contábeis e Administração (FURB), Professora do Programa de PósGraduação em Ciências Contábeis da Universidade Federal de Santa Maria (PPGCC/UFSM). Endereço: Av. Roraima, $n^{\circ}$ 1000, Cidade Universitária, CCSH, Prédio 74C, Sala 4344, $3^{\circ}$ Andar, Bairro Camobi, CEP: 97.105-900, Santa Maria/RS, Brasil. E-mail: lari_ipo@hotmail.com https://orcid.org/0000-0003-0651-8540

5 Doutor em Ciências Contábeis (UNISINOS), Professor do Programa de Pós-Graduação em Ciências Contábeis da Universidade Federal de Santa Maria (PPGCC/UFSM). Endereço: Av. Roraima, $n^{\circ}$ 1000, Cidade Universitária, CCSH, Prédio 74C, Sala 4442, $4^{\circ}$ Andar, Bairro Camobi, CEP: 97.105-900, Santa Maria/RS, Brasil. E-mail: Iuizmarquezan@gmail.com https://orcid.org/0000-0003-2935-3099

Editor responsável pela aprovação do artigo: Dr. João Estevão Barbosa Neto Editora responsável pela edição do artigo: Dr ${ }^{a}$. Bruna Camargos Avelino 
capital psicológico influencia positivamente a motivação para aprendizagem e também exerce influência direta e significativa sobre a aquisição de conhecimentos. Essas evidências mostram que, quando os alunos desenvolvem seu capital psicológico, que é conceituado por Luthans et al. (2015) como o estado psicológico positivo do desenvolvimento de um indivíduo e é composto por quatro capacidades: autoeficácia, esperança, otimismo e resiliência, seu comportamento para aprendizagem é potencializado e, nessas condições, sua capacidade para aquisição de novos conhecimentos também é elevada. A motivação para aprendizagem também apresentou influência positiva na aquisição de conhecimentos, o que indica que atua como mediadora da relação entre capital psicológico e aquisição de conhecimentos. Essa mediação é complementar, em que os efeitos do capital psicológico são diretos e indiretos na aquisição de conhecimentos. Conclui-se que alunos com maior nível de capital psicológico são mais motivados para aprender e tendem a apresentar maiores níveis de conhecimentos adquiridos no curso de Ciências Contábeis. Estes achados contribuem com a gestão do curso, pois podem auxiliar no desenvolvimento de ações, no intuito de potencializar o capital psicológico dos alunos e sua motivação para aprendizagem, que refletirão positivamente na aquisição de conhecimentos.

Palavras-chave: Capital psicológico. Motivação para aprender. Aquisição de conhecimentos.

\section{INFLUENCE OF PSYCHOLOGICAL CAPITAL ON MOTIVATION FOR LEARNING AND ACQUISITION OF KNOWLEDGE}

\section{ABSTRACT}

The research analyzes the influence of psychological capital on the motivation for learning and adquired knowledge of students of a face-to-face undergraduate course in Accounting. Descriptive research was carried out by surveying 235 students from an $\mathrm{HEl}$ and using a quantitative approach, using structural equation modeling. Three hypotheses were investigated, which deal with the direct influence of psychological capital on the motivation for learning $(\mathrm{HI})$ and on the acquisition of knowledge $(\mathrm{H} 2)$ and the mediating effects of motivation for learning on the relationship between psychological capital and knowledge acquisition $(\mathrm{H} 3)$. The results revealed that psychological capital positively influences the motivation for learning and also exerts a direct and significant influence on the acquisition of knowledge. This evidences shows that when students develop their psychological capital, which is conceptualized by Luthans et al. (2015) as the positive psychological state of an individual's development and is composed of four capacities: self-efficacy, hope, optimism and resilience, their learning behavior is enhanced and, under these conditions, their ability to acquire new knowledge is also high. The motivation for learning also had a positive influence on the acquisition of knowledge, which indicates that it acts as a mediator of the relationship between psychological capital and knowledge acquisition. This mediation is complementary, in which the effects of psychological capital are direct and indirect in the acquisition of knowledge. It is concluded that students with a higher level of psychological capital are more motivated to learn and tend 
to have higher levels of knowledge acquired in the Accounting course. These findings contribute to the management of the course, as they can assist in the development of actions, in order to enhance the psychological capital of students and their motivation for learning, which will reflect positively on the acquisition of knowledge.

Keywords: Psychological capital. Motivation to learn. Acquisition of knowledges.

\section{INTRODUÇÃO}

A abordagem comportamental da contabilidade investiga, a partir do uso de teorias da psicologia, elementos que influenciam as cognições, a ação e o desenvolvimento humano (Birnberg et al., 2007; Baldvinsdottir et al., 2010). Elementos de análise da psicologia positiva têm sido utilizados em investigações realizadas na área comportamental da contabilidade, como nos estudos de Venkatesh e Blaskovich (2012) e Pletsch e Zonatto (2018), que observaram, dentre outras variáveis, os efeitos do capital psicológico no comportamento dos indivíduos.

O capital psicológico é definido como um fator psicológico de positividade, composto por um conjunto integrado de diversas capacidades psicológicas positivas (Luthans et al., 2007). Constitui-se um estado mental positivo, em que há quatro capacidades psicológicas positivas para auxiliar o indivíduo no desenvolvimento de suas atividades, sendo essas denominadas de autoeficácia, esperança, otimismo e resiliência (Luthans et al., 2007). Conforme os autores, deve-se considerar que esse conjunto de capacidades psicológicas é indissociável do capital psicológico na análise, uma vez que as capacidades psicológicas estão inter-relacionadas.

Estudos desenvolvidos na área contábil analisaram os efeitos do capital psicológico na motivação para aprendizagem e aquisição de conhecimentos (Pletsch \& Zonatto, 2018) e os efeitos da motivação para aprendizagem na aquisição de conhecimentos (Tho, 2017; Pletsch \& Zonatto, 2018). Ambas as relações apresentaram evidências de resultados positivos, o que indica que indivíduos que possuem o capital psicológico desenvolvido, apresentam motivação para o aprendizado e consequentemente adquirem novos conhecimentos.

Cohen e Levinthal (1990) abordam que para desenvolver a capacidade de aquisição de forma eficaz, seja para conhecimentos, habilidades para resolver problemas ou aprender, é insuficiente apenas expor o indivíduo a um conhecimento anterior relevante. "A intensidade do esforço é um elemento crítico" (Cohen \& Levinthal, 1990, p. 131), o que revela a importância das capacidades psicológicas de autoeficácia, esperança, otimismo e resiliência para a motivação para a aprendizagem e aquisição de conhecimentos.

Conforme Riolli et al. (2012, p. 1203), "as pessoas com elevado capital psicológico perceberão 0 ambiente como mantendo aspectos mais desafiadores, com o potencial de benefícios como prazer, aprendizado e crescimento pessoal". Portanto, as capacidades psicológicas que compõem o capital psicológico humano são importantes para que os indivíduos possam se desenvolver e apresentar comportamentos positivos que venham a contribuir 
para o alcance dos objetivos desejados. Esses comportamentos refletem no nível de esforço que o indivíduo está disposto a empreender para esse fim (Venkatesh \& Blaskovich, 2012; Pletsch \& Zonatto, 2018).

Nas organizações, indivíduos comprometidos tendem a se esforçar mais para executar suas atribuições de trabalho, o que refletirá positivamente nos resultados organizacionais (Wong-On-Wing et al., 2010). Nesse sentido, "como o ensino superior é responsável por educar os alunos para atender as demandas sociais e organizacionais, deve-se prestar atenção ao capital psicológico dos alunos" (You, 2016, p. 17), visto os seus efeitos positivos na motivação para aprendizagem e aquisição de novos conhecimentos no ambiente acadêmico (Pletsch \& Zonatto, 2018), fato este que estimula a realização desta pesquisa.

Embora níveis mais baixos de capital psicológico "não reduz diretamente o conhecimento, as habilidades de um indivíduo, este pode minimizar no indivíduo a confiança necessária para ter sucesso em uma tarefa e/ou exibir comportamentos no trabalho" (Thompson et al., 2015, p. 188). Diante de uma perspectiva positiva, níveis mais altos de capital psicológico podem ajudar os indivíduos nos contratempos ou aprimorar a sua capacidade de utilizar habilidades e conhecimentos, proporcionando-lhe "coragem e entusiasmo para alcançar seus objetivos" (Thompson et al., 2015, p. 189). Deste modo, a motivação para aprendizagem pode auferir efeitos significativos e indiretos no potencial do capital psicológico para com a aquisição de conhecimentos.

De acordo com Blumenfeld et al. (2006, p. 476), "a motivação prepara o indivíduo para o engajamento cognitivo", ocasiona a conquista e aumenta a qualidade do envolvimento cognitivo. Assim, "a compreensão do conteúdo e as habilidades são aprimoradas quando os alunos se comprometem a construir conhecimento e empregar estratégias de aprendizado mais profundas", por meio da motivação que possuem. Logo, a motivação para aprendizagem "pode levar a um envolvimento mais profundo com o material, o que resulta em aumento de habilidades e conhecimentos" (Blumenfeld et al., 2006, p. 476).

A partir das razões apresentadas para a análise dos efeitos diretos do capital psicológico na motivação para aprendizagem e aquisição de conhecimentos, bem como, os efeitos indiretos da motivação na relação entre capital psicológico e aquisição de conhecimentos, destaca-se que foi encontrado apenas um estudo que investigou os relacionamentos propostos nesta pesquisa (Pletsch \& Zonatto, 2018) e o estudo de Tho (2017) que analisou a relação entre a motivação para aprendizagem e o conhecimento adquirido, mas não observou os efeitos intervenientes do capital psicológico.

Contudo, ambos os estudos de Tho (2017) e Pletsch e Zonatto (2018) não observaram os efeitos de variáveis demográficas (idade e sexo) e contextuais (semestre, quantidade de disciplinas em curso e carga horária de trabalho semanal) que podem explicar eventuais diferenças na amostra analisada (Poots \& Cassidy, 2020), lacuna teórica explorada nesta investigação. Uma vez que o nível de análise é o indivíduo, torna-se necessário se compreender como características pessoais e contextuais interferem em tais relacionamentos, o que contribui para o avanço dos conhecimentos existentes sobre o tema.

Poots e Cassidy (2020) analisaram o capital psicológico e variáveis comportamentais de estudantes do ensino superior, com a consideração de variáveis demográficas e contextuais. Os resultados revelaram a importância da 
análise de tais fatores no ambiente universitário para explicar os achados encontrados, revelando que tais fatores são capazes de explicar diferenças entre as capacidades psicológicas dos estudantes, razão pela qual esta análise adiciona possíveis explicações para a presente pesquisa e o estudo de Pletsch e Zonatto (2018).

Considerando-se que os indivíduos diferem em suas capacidades psicológicas (Bandura, 1986; Luthans et al., 2007) e que as evidências encontradas na literatura para os relacionamentos propostos nesta pesquisa ainda podem ser consideradas incipientes, torna-se oportuna a avaliação de tais relacionamentos, o que contribui para o desenvolvimento da área comportamental da contabilidade (Zonatto et al., 2019; Poots \& Cassidy, 2020). A análise desses elementos não observados em estudos anteriores também contribui para com o avanço dos conhecimentos existentes sobre os temas abordados nesta pesquisa.

Nesse contexto, este estudo busca responder à seguinte questão: Qual a influência do capital psicológico na motivação para aprendizagem e aquisição de conhecimentos de estudantes de Ciências Contábeis de uma instituição de ensino superior? Como objetivo, busca-se avaliar a influência do capital psicológico na motivação para aprendizagem e aquisição de conhecimentos de estudantes de um curso de graduação presencial em Ciências Contábeis. Adicionalmente, serão observadas características individuais (idade e sexo) e contextuais (semestre, quantidade de disciplinas em curso e carga horária de trabalho semanal) a que estes indivíduos estão expostos, que podem explicar eventuais diferenças entre a amostra analisada (Poots \& Cassidy, 2020).

Este estudo se justifica pela oportunidade de se compreender as interações existentes entre elementos cognitivos (capital psicológico) e motivacionais (motivação para aprendizagem) que influenciam a aquisição de conhecimentos de alunos do ensino superior, mais precisamente, do curso de Ciências Contábeis, aspectos pouco estudados nesta área. Conforme You (2016), mais pesquisas empíricas sobre o capital psicológico são necessárias no contexto acadêmico, o que justifica a realização deste estudo. Optou-se por analisar acadêmicos de um curso de graduação em ciências contábeis, em função da acessibilidade dos dados.

As contribuições sociais desta pesquisa refletem em alunos, professores e gestores de instituições de ensino, em especial do curso de Ciências Contábeis. A partir das evidências encontradas, os alunos podem compreender a influência de suas cognições no processo de motivação e aprendizagem. Por sua vez, os professores poderão compreender os fatores que afetam a aquisição de conhecimentos pelos alunos, a partir de uma perspectiva de análise dos indivíduos, considerando que esses diferem em suas capacidades psicológicas. Para a gestão do curso, pode auxiliar na promoção de ações, no intuito de potencializar o desenvolvimento do capital psicológico positivo dos alunos e sua motivação para aprendizagem.

Na perspectiva teórica, este estudo apresenta evidências que auxiliam na compreensão da aquisição de conhecimentos, das relações existentes entre o capital psicológico, a motivação para aprendizagem e a aquisição de conhecimentos, bem como os efeitos de variáveis que são capazes de discriminar tais aspectos na amostra analisada. As evidências encontradas também 
permitem entender como um grupo específico de alunos do curso de Ciências Contábeis consegue se motivar e, com isso, desenvolver suas capacidades psicológicas de autoeficácia, esperança, otimismo e resiliência para efetivamente adquirir novos conhecimentos, empreendendo maior esforço para aprender e assim, obter sucesso na carreira profissional.

\section{APORTE TEÓRICO E HIPÓTESES DA PESQUISA}

O capital psicológico é formado por quatro capacidades psicológicas positivas de autoeficácia, esperança, otimismo e resiliência que são mensuráveis e podem ser desenvolvidas nos indivíduos e tem impacto positivo sobre o desempenho destes nas organizações (Luthans et al., 2004; Siqueira, 2014). Segundo Siqueira (2014), a autoeficácia é definida como a crença que o indivíduo detém em relação à sua capacidade de mobilizar a motivação, os recursos cognitivos e o curso de ação necessários para realizar com êxito uma tarefa específica.

Luthans et al. (2007), abordam que a esperança é um estado cognitivo no qual o indivíduo acredita alcançar seus objetivos por meio da sua determinação, sendo capaz de gerar caminhos para alcançar seus objetivos e metas. $O$ otimismo refere-se à "crença que o indivíduo detém de que os acontecimentos positivos são atribuídos a causas individuais, permanentes e universais" (Siqueira, 2014, p. 67). Por fim, a resiliência refere-se à capacidade do indivíduo de se recuperar de adversidades, conflitos, fracassos e superar mudanças positivas diante do aumento de responsabilidades (Luthans et al., 2015).

O capital psicológico aborda elementos positivos que potencializam o desenvolvimento e a ação dos indivíduos (Luthans et al., 2007). Nesse sentido, o capital psicológico pode ser considerado um fator que tende a afetar a motivação para aprendizagem e os conhecimentos adquiridos pelos indivíduos (Pletsch \& Zonatto, 2018). No âmbito do trabalho, a motivação possui relação direta com a produtividade individual e organizacional (Zonatto et al., 2018).

O desempenho do aluno será melhor quando a motivação estiver em um nível médio, o que significa que a motivação muito baixa não promove a ação para aprender, pois o indivíduo não tem desejo, não é proativo e não irá se esforçar para esse fim. Por outro lado, a motivação muito alta pode gerar estresse, cansaço e ansiedade, prejudicando o raciocínio e a recuperação de informações necessárias para aprender (Nunes \& Silveira, 2015). Riolli et al. (2012) acreditam que pessoas com esperança, otimismo, ego resiliente e com autoeficácia terão mais chances de acreditar que possuem recursos positivos suficientes para lidar com um ambiente estressante. Logo, tais capacidades psicológicas juntas, sugerem que os alunos com alto capital psicológico serão mais eficazes de lidar com o estresse acadêmico e manter o bem-estar físico e psicológico (Riolli et al., 2012), o que tende a impactar positivamente na sua motivação para aprendizagem e aquisição de conhecimentos (Pletsch \& Zonatto, 2018).

O conhecimento é incorporado na memória das pessoas e demonstrado por meio de suas ações e comportamentos. A capacidade de identificar, assimilar, aplicar o conhecimento adquirido e se motivar a aprender novos conhecimentos é o que atribui importância e utilidade ao conhecimento 
adquirido (Tho, 2017). Mesmo que o indivíduo possua motivação para aprender e que haja aquisição de conhecimentos, é a sua capacidade de aprendizagem e de absorção de novos conhecimentos que irá determinar como os novos conhecimentos serão armazenados em sua memória e utilizados posteriormente (Pletsch \& Zonatto, 2018). A aprendizagem se refere à mudança de comportamento e pode ser analisada sob vários ângulos. Na perspectiva da agência humana, Bandura (1989; 2008) explica que nem todos os indivíduos se desenvolvem, mesmo estando expostos a condições que possam favorecer a aprendizagem.

Há que se considerar que os indivíduos possuem capacidades psicológicas positivas distintas, razão pela qual podem apresentar diferentes comportamentos em um contexto de interação social, como é o caso do ambiente de trabalho (Pletsch \& Zonatto, 2018) e o acadêmico. Nesta perspectiva, é possível se admitir que as crenças de autoeficácia, esperança, otimismo e resiliência podem atuar como um preditor da motivação para aprendizagem e aquisição de conhecimentos de alunos do ensino superior. Além disso, que a motivação para aprendizagem pode mediar a relação entre o capital psicológico e a aquisição de conhecimentos.

Neste contexto, busca-se investigar tais relacionamentos, a partir do modelo teórico de análise apresentado na Figura 1.

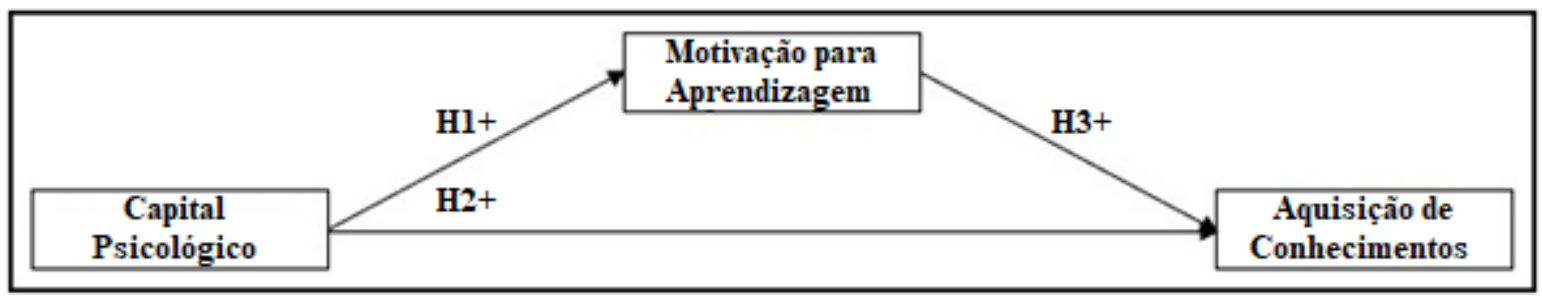

Figura 1 Modelo teórico do estudo

Fonte: Elaborado pelos autores.

Conforme Luthans et al. (2007), o capital psicológico refere-se às motivações individuais que se acumulam por meio de construções psicológicas positivas, influenciando as ações e os comportamentos dos indivíduos. Por representar recursos psicológicos positivos de um indivíduo, é capaz de influenciar o nível de esforço que este estará disposto a empreender para o alcance de um determinado objetivo (Thompson et al., 2015). De acordo com Ersanlı (2015) tanto a autoeficácia que é definida como uma crença que o indivíduo possui para executar uma tarefa com sucesso, quanto a motivação que consiste nos fatores internos e externos que estimulam o desejo de atingir um objetivo, são as forças que levam as pessoas a perseguir uma meta e superar os obstáculos, pois indivíduos com maior autoeficácia e motivação fazem o melhor e não desistem facilmente diante de dificuldades.

Evidências encontradas na literatura têm sugerido uma relação positiva e significativa entre o capital psicológico e a motivação para aprender (Pletsch \& Zonatto, 2018). Da mesma forma, os resultados revelam que os níveis de motivação para aprender e aquisição de conhecimentos dos alunos diferem, assim como seu capital psicológico (Pletsch \& Zonatto, 2018). Uma vez que o capital psicológico é concebido como um antecedente à motivação e à aquisição de conhecimentos, e considerando-se que essas capacidades 
psicológicas variam entre os indivíduos (Pletsch \& Zonatto, 2018), tais relacionamentos precisam ser avaliados, de modo que se possa melhor compreender os efeitos das capacidades psicológicas em tais variáveis e os fatores que explicam eventuais diferenças (Poots \& Cassidy, 2020).

Uma possível explicação para as dificuldades de aprendizagem apresentadas por alunos, pode estar relacionada aos aspectos de dificuldades, interesses, desejos ou de condicionantes pessoais e contextuais, elementos não observados nos estudos realizados anteriormente por Tho (2017) e Pletsch e Zonatto (2018). Nesse sentido, acredita-se que alunos com maiores níveis de capital psicológico apresentam maiores níveis de motivação para aprender, conforme a hipótese do estudo: $H_{l}$. $O$ capital psicológico influencia positivamente a motivação para aprendizagem.

O conhecimento é adquirido quando um indivíduo desenvolve um conjunto de capacidades cognitivas que lhe permite reconhecer o valor de uma informação, assimilá-la e aplicá-la (Cohen \& Levinthal, 1990; Pletsch \& Zonatto, 2018). Possui origem em informações interpretadas, transformadas e enriquecidas pelo indivíduo, que estão armazenadas em sua memória (Bender \& Fish, 2000) e sofre influência de aspectos cognitivos, como as capacidades psicológicas positivas (Luthans et al., 2007). Evidências encontradas na literatura contábil confirmam relação positiva entre o capital psicológico e o conhecimento adquirido por acadêmicos do curso de Ciências Contábeis (Pletsch \& Zonatto, 2018).

No contexto de atuação do profissional da área de Ciências Contábeis, espera-se que os estudantes sejam capazes de desenvolver conhecimentos que Ihe permitam atender as exigências do mercado de trabalho (Tamer et al., 2013). Espera-se que sejam capazes de desenvolver não apenas competências técnicas, mas também competências e habilidades que lhe permitirão aprimorar aptidões para resolução de problemas, pensamento crítico e capacidade analítica (Pan \& Perera, 2012), elementos considerados relevantes para 0 atendimento das necessidades do mercado de trabalho.

As mudanças no mercado, as novas tecnologias no trabalho e o seu autodesenvolvimento são fatores que motivam o indivíduo a aprender, para poder se desenvolver no seu trabalho (Comin et al., 2011). Esses aspectos tendem a influenciar a forma como esses indivíduos irão se comportar em sala de aula, aproveitando as condições de ensino, para que ocorra a aquisição de novos conhecimentos (Tho, 2017). Estes, quando adquiridos poderão ser incorporados às atividades de trabalho dos indivíduos, impactando diretamente no desempenho de suas tarefas (Pletsch \& Zonatto, 2018).

Portanto, a aprendizagem é um processo ativo por meio do qual os alunos constroem novos conceitos baseados nos seus conhecimentos passados ou atuais. O aluno seleciona e transforma as informações, constrói hipóteses e toma decisões baseadas em sua própria estrutura cognitiva (Comin et al., 201 1). Nesse contexto, espera-se que o capital psicológico seja capaz de atuar como um facilitador ao interesse do aluno pela aquisição de novos conhecimentos e a sua posterior aplicação na organização que trabalha. Tais argumentos propõem que: $\mathrm{H}_{2}$. O capital psicológico influencia positivamente o conhecimento adquirido.

A motivação para aprender influencia a capacidade do indivíduo de identificar, assimilar e aplicar um novo conhecimento adquirido. Também exerce 
influência na atribuição de importância e utilidade ao novo conhecimento (Tho, 2017; Pletsch \& Zonatto, 2018). Portanto, exerce influência nas percepções e cognições individuais dos alunos, sobre a necessidade de aquisição e de aprendizagem de um novo conhecimento (Nunes \& Silveira, 2015).

De acordo com Blumenfeld et al. (2006), a motivação ajuda a estabelecer e aumentar a qualidade do engajamento cognitivo, levando o indivíduo a obter sucesso. A compreensão dos conteúdos e as habilidades são aprimoradas, a partir do momento em que os acadêmicos se comprometem a construir conhecimento e implantar estratégias de aprendizagem profundas (Blumenfeld et al., 2006). Tais constatações presumem que a motivação para aprender pode potencializar a relação entre o capital psicológico e a aquisição de conhecimentos. Acadêmicos com níveis mais altos de motivação para aprender possuem maiores probabilidades de se equipar a um aprendizado mais eficaz e utilizar estratégias que facilitam a aquisição de conhecimentos (Nguyen \& Nguyen, 2010), sendo este processo melhorado por meio do desenvolvimento do capital psicológico. Para tanto, se a motivação para aprender é elevada, é mais provável que os objetivos dos acadêmicos sejam alcançados (Tho, 2017).

Estudos desenvolvidos por Tho (2017) e Pletsch e Zonatto (2018) confirmaram uma relação positiva e significativa entre a motivação para aprender e o conhecimento adquirido, o que sugere que a motivação para aprender, quando potencializada pelo capital psicológico influencia o conhecimento adquirido pelos indivíduos. Espera-se que a motivação para aprendizagem exerça influência direta na aquisição de novos conhecimentos e seja capaz de mediar a relação entre o capital psicológico e a aquisição de conhecimentos. A partir do exposto, elaborou-se a seguinte hipótese: $H_{3}$. A motivação para aprendizagem medeia positivamente a relação entre o capital psicológico e o conhecimento adquirido.

\section{PROCEDIMENTOS METODOLÓGICOS}

Esta pesquisa é caracterizada como descritiva, realizada por meio de um levantamento e com abordagem quantitativa dos dados. A população deste estudo é composta por 410 acadêmicos do curso de Ciências Contábeis de uma Instituição pública de Ensino Superior (IES), localizada na região central do estado do Rio Grande do Sul (RS). Justifica-se a análise de estudantes do curso de ciências contábeis e de uma IES, diante da acessibilidade dos dados.

A amostra foi constituída por 235 respondentes. Para compor a amostra, apenas foram selecionados os alunos que já trabalham ou que estavam trabalhando no momento da aplicação do questionário, pois a experiência com o mercado de trabalho poderia reduzir o viés nas respostas. Além disso, justificase a opção por participantes que já haviam alguma experiência no mercado de trabalho, ou que estavam trabalhando, pois conforme Riolli et al. (2012, p. 1205), "o ambiente de trabalho acadêmico para estudantes contém muitas das mesmas dificuldades evidentes em um ambiente organizacional", por isso a importância da seleção de tais acadêmicos. Tais procedimentos são convergentes aos adotados em estudos desenvolvidos sobre o tema capital psicológico no ambiente acadêmico (Pletsch \& Zonatto, 2018). 
Para a obtenção dos dados, elaborou-se um instrumento de pesquisa (questionário, disponibilizado em anexo) adaptado dos estudos de Luthans et al. (2007), para medir o capital psicológico e de Tho (2017), para mensurar a motivação para aprendizagem e aquisição de conhecimentos. O questionário foi estruturado em dois blocos. O primeiro bloco diz respeito a caracterização da amostra de estudantes participantes da pesquisa. O segundo bloco compreendeu os questionamentos sobre o capital psicológico, motivação para aprendizagem e aquisição de conhecimentos. As perguntas do segundo bloco foram estruturadas em escala Likert de 7 pontos, sendo 1 (fortemente em desacordo) até 7 (concordo fortemente).

Para medir o capital psicológico foi utilizada a versão reduzida (PCQ-12) proposta por Luthans et al. (2007). Optou-se por esta versão, pois foi utilizada na contemporaneidade por diversos estudos na área acadêmica, como por exemplo Riolli et al. (2012), You (2016), Pletsch e Zonatto (2018) e Poots e Cassidy (2020). Além disso, utilizou-se o questionário desenvolvido por Luthans et al. (2007), visto que tanto o constructo original de 24 indicadores, quanto o suprimido de 12 indicadores foi elogiado por Luthans et al. (2015), visto que é um constructo de ordem superior, composto por 4 constructos de suporte e tem sido muito utilizado na literatura para medir o capital psicológico (Poots \& Cassidy, 2020). A Tabela 1 apresenta o constructo elaborado para a realização do estudo. 


\section{Tabela 1}

Constructo do estudo

\begin{tabular}{|c|c|c|c|c|}
\hline Var. & Operacionalização & Definição & Questões & Autores \\
\hline $\mathrm{CP}$ & $\begin{array}{l}\text { - Autoeficácia (AE) } \\
\text { - Esperança (ES) } \\
\text { - Otimismo (OT) } \\
\text { - Resiliência (RE) }\end{array}$ & $\begin{array}{l}\text { "É um estado psicológico positivo de } \\
\text { desenvolvimento do indivíduo e } \\
\text { caracteriza-se por: (1) ter confiança } \\
\text { (autoeficácia) para despender esforços } \\
\text { necessários para ser bem sucedido em } \\
\text { tarefas desafiadoras; (2) fazer uma } \\
\text { atribuição positiva (otimismo) acerca dos } \\
\text { acontecimentos que vão ocorrer no } \\
\text { presente e no futuro; (3) perseverar em } \\
\text { direção a metas, e quando necessário, } \\
\text { redirecionar caminhos para metas } \\
\text { (esperança) e para ter sucesso; e, (4) } \\
\text { quando necessário, apresenta-se capaz } \\
\text { de redirecionar os meios para atingir os } \\
\text { fins, revelando a capacidade para } \\
\text { recuperar e lidar com as adversidades } \\
\text { (resiliência)" (Luthans et al., 2007, p. 3). }\end{array}$ & 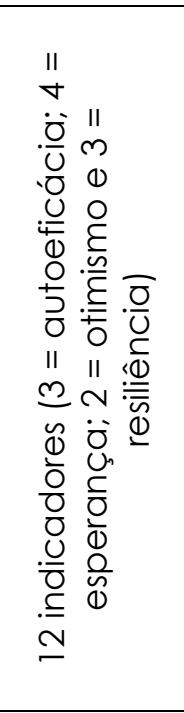 & $\begin{array}{l}\text { Luthans } \\
\text { et al. } \\
\text { (2007) }\end{array}$ \\
\hline MPA & $\begin{array}{c}\text { - Participação e } \\
\text { aprendizado dos } \\
\text { acadêmicos }\end{array}$ & $\begin{array}{l}\text { A motivação é aquilo que move uma } \\
\text { pessoa, a coloca em ação ou a faz } \\
\text { mudar de curso (Wong-On-Wing et al., } \\
\text { 2010). Os indivíduos que possuem altos } \\
\text { níveis de motivação para aprender } \\
\text { tendem a ser mais eficazes na aquisição } \\
\text { de conhecimentos (Tho, 2017). }\end{array}$ & $\begin{array}{l}\tilde{0} \\
\overline{0} \\
\frac{0}{0} \\
. \frac{0}{0} \\
. \subseteq \\
i n\end{array}$ & \\
\hline$C A$ & $\begin{array}{l}\text { Habilidades e } \\
\text { Capacidades }\end{array}$ & $\begin{array}{l}\text { "O conhecimento [...] se baseia em } \\
\text { informações que são transformadas e } \\
\text { enriquecidas por experiências pessoais, } \\
\text { crenças e valores com significado } \\
\text { relevante para a decisão e a ação. São } \\
\text { informações interpretadas pelo indivíduo } \\
\text { e aplicadas ao objetivo para o qual são } \\
\text { necessárias" (Bender \& Fish, 2000, p. 126). }\end{array}$ & $\begin{array}{l}\tilde{0} \\
\frac{0}{0} \\
\frac{0}{0} \\
\frac{.}{0} \\
. \frac{.}{0}\end{array}$ & (2017) \\
\hline
\end{tabular}

Legenda: CP. Capital Psicológico; MPA. Motivação para Aprendizagem; CA. Conhecimentos Adquiridos.

Fonte: Dados da pesquisa.

Após a elaboração do questionário e antes da etapa de coleta de dados, foi realizado um pré-teste com três alunos concluintes do curso de Ciências Contábeis, a fim de avaliar a sua compreensão do questionário, e, a seguir, procedeu-se também a realização de uma consulta junto ao Conselho de Pesquisa (CEPE) da Unidade de Ensino, para se verificar a necessidade de sua tramitação no CEPE. Em relação ao pré-teste realizado, verificou-se que os participantes tiveram facilidade para compreender as assertivas, sendo assim, nenhum ajuste foi necessário no questionário, estando este apto à sua aplicação.

Em relação a consulta realizada, a Comissão de Pesquisa da Unidade de Ensino estudada entendeu que por não haver questões abertas, sendo o instrumento de pesquisa já validado e utilizado em outros estudos, e por não haver a identificação dos sujeitos participantes da pesquisa, não haveria a necessidade de tramitação de processo no CEPE. No entanto, recomendou que alguns procedimentos fossem adotados, quando da aplicação em sala de aula do instrumento utilizado para a coleta de dados. Estes procedimentos foram 
adotados, sendo que a pesquisa aplicada foi regida pelos princípios gerais relativos: (i) ao consentimento informado; (ii) a preocupação em não prejudicar a entidade e as pessoas que nela trabalham; e, (iii) manter a confidencialidade das pessoas e da entidade.

Assim, quando da realização da coleta de dados, os seguintes procedimentos foram adotados para assegurar confidencialidade dos participantes da pesquisa e da entidade estudada: a) O respondente participará da pesquisa voluntariamente, se assim desejar; b) O respondente terá liberdade de desistir ou de interromper a colaboração nesta pesquisa no momento em que desejar, sem necessidade de qualquer explicação; c) O questionário aplicado não solicitará nenhuma identificação individual pessoal do estudante; d) Apenas os pesquisadores envolvidos terão acesso aos questionários respondidos; e) Ao preencher voluntariamente e entregar o instrumento de coleta de dados, 0 respondente concorda que sejam divulgados os resultados da pesquisa em publicações científicas; e, f) Qualquer dúvida referente ao questionário pode ser esclarecida com os pesquisadores responsáveis pela execução da pesquisa realizada.

Desta forma, todos os estudantes presentes em sala de aula no momento da aplicação do questionário receberam todas estas orientações antes do preenchimento voluntário do instrumento de coleta de dados. Assim, somente entregaram os questionários utilizados nesta pesquisa, aqueles estudantes que voluntariamente concordaram com a realização do trabalho, sob tais condições. Uma cópia do Termo de Consentimento Livre e Esclarecido (TCLE) elaborado para o trabalho e lida para os estudantes antes do momento da aplicação do questionário, encontra-se em anexo, a qual também foi disponibilizada aos estudantes interessados em acessá-la em formulário impresso. O questionário foi impresso e aplicado aos alunos pessoalmente nas salas de aulas, durante o período de $1^{\circ}$ a 11 de abril de 2019.

Todos os questionários coletados foram analisados e considerados válidos, não havendo desistência de respondentes durante o preenchimento das respostas e questionários com respostas incompletas. Com isso, foi obtido um total de 235 respostas válidas, as quais foram analisadas na pesquisa. As respostas obtidas foram tabuladas em planilha eletrônica do Excel e importadas aos softwares SPSS ${ }^{\circledR}$ e AMOS ${ }^{\circledR}$ para tratamento estatístico, conforme procedimentos adotados por Pletsch e Zonatto (2018).

Inicialmente, procedeu-se à análise descritiva dos indicadores de cada constructo. Na sequência, foi realizada a análise fatorial confirmatória dos constructos de mensuração, para que fosse possível inferir sobre sua validade teórica. Posteriormente, procedeu-se à análise de sua validade discriminante, pelo critério de Bagozzi e Philips (1982). Na sequência, realizou-se à modelagem de equações estruturais, para inferir sobre as relações objeto de estudo.

Por fim, desenvolveu-se uma análise adicional, por meio da utilização da regressão linear múltipla, com vistas a analisar se as variáveis pessoais e contextuais (faixa etária, sexo, semestre letivo, quantidade de disciplinas e carga horária de trabalho semanal) dos acadêmicos podem explicar eventuais diferenças no que tange aos constructos analisados sobre o capital psicológico, motivação para a aprendizagem e aquisição de conhecimentos. As razões teóricas para a realização desta análise, provém de estudos realizados na área 
comportamental da contabilidade, como por exemplo, o estudo de Zonatto et al. (2019) e Poots e Cassidy (2020), que constataram que o perfil da amostra pode ter refletido nos resultados obtidos.

A Tabela 2 apresenta os indicadores utilizados para a etapa de validação dos constructos de mensuração e a análise do objetivo do estudo, a partir da adoção dos procedimentos de modelagem por equações estruturais recomendados por Hair Jr. et al. (2009).

\section{Tabela 2}

Critérios utilizados para avaliar o ajuste dos modelos de mensuração

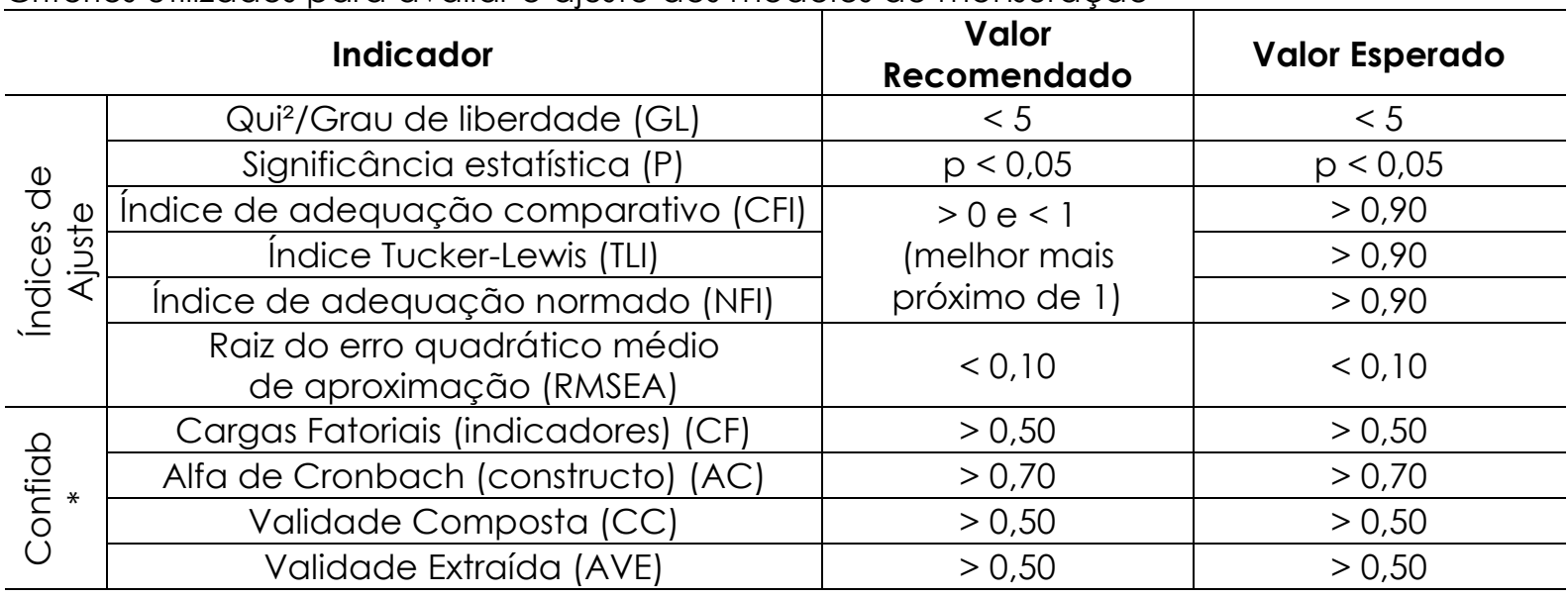

*Confiabilidade.

Fonte: Adaptado de Pletsch e Zonatto (2018).

Os índices de confiabilidade adotados medem o coeficiente fatorial dos indicadores (CF) e dos constructos de mensuração (AC), sua consistência interna (CC) e a variância extraída (AVE). Já os índices de ajuste permitem inferir a qualidade preditiva do modelo de mensuração adotado (Hair Jr. et al., 2009). Nesta pesquisa, esses indicadores são analisados em conjunto.

\section{RESULTADOS DA PESQUISA}

\subsection{Caracterização da Amostra}

A Tabela 3 apresenta os resultados da caracterização da amostra analisada. 
Tabela 3

Caracterização dos respondentes da pesquisa

\begin{tabular}{l|c|c|c|c|c}
\hline \multicolumn{1}{c|}{ Sexo } & Fi Abs. & Fi Rel. & Semestre Letivo & Fi Abs. & Fi Rel. \\
\hline Feminino & 105 & $44,68 \%$ & $1^{\circ}$ Semestre & 33 & $14,04 \%$ \\
\hline Masculino & 130 & $55,32 \%$ & $2^{\circ}$ Semestre & 32 & $13,62 \%$ \\
\hline Totais & $\mathbf{2 3 5}$ & $\mathbf{1 0 0 \%}$ & $3^{\circ}$ Semestre & 21 & $8,94 \%$ \\
\hline \multicolumn{1}{c|}{ Faixa Etária } & Fi Abs. & Fi Rel. & $4^{\circ}$ Semestre & 28 & $11,91 \%$ \\
\hline Até 18 anos & 22 & $9,36 \%$ & $5^{\circ}$ Semestre & 30 & $12,77 \%$ \\
\hline Entre 19 e 24 anos & 152 & $64,68 \%$ & $6^{\circ}$ Semestre & 12 & $5,11 \%$ \\
\hline Entre 25 e 30 anos & 30 & $12,77 \%$ & $7^{\circ}$ Semestre & 25 & $10,64 \%$ \\
\hline Entre 31 e 35 anos & 19 & $8,09 \%$ & $8^{\circ}$ Semestre & 20 & $8,51 \%$ \\
\hline Mais de 35 anos & 12 & $5,11 \%$ & $9^{\circ}$ Semestre & 31 & $13,19 \%$ \\
\hline Totais & $\mathbf{2 3 5}$ & $\mathbf{1 0 0 \%}$ & $10^{\circ}$ Semestre & 3 & $1,28 \%$ \\
\hline Carga Horária de Trabalho* & Fi Abs. & Fi Rel. & Totais & $\mathbf{2 3 5}$ & $\mathbf{1 0 0 \%}$ \\
\hline Até 12 horas & 11 & $4,68 \%$ & & & \\
\hline entre 13 e 20 horas & 61 & $25,96 \%$ & Qtd. Disciplinas & Fi Abs. & Fi Rel. \\
\hline entre 21 e 30 horas & 53 & $22,55 \%$ & Até 3 disciplinas & 37 & $15,74 \%$ \\
\hline entre 31 e 39 horas & 14 & $5,96 \%$ & Entre 4 e 5 disciplinas & 135 & $57,45 \%$ \\
\hline 40 horas ou mais & 96 & $40,85 \%$ & 6 ou mais disciplinas & 63 & $26,81 \%$ \\
\hline Totais & $\mathbf{2 3 5}$ & $\mathbf{1 0 0 \%}$ & Totais & $\mathbf{2 3 5}$ & $\mathbf{1 0 0 \%}$ \\
\hline Legenda: & & &
\end{tabular}

Legenda: Fi Abs. Frequência absoluta; Fi Rel. Frequência relativa. ${ }^{*}$ Carga horária de trabalho semanal.

Fonte: Dados da pesquisa.

A amostra da pesquisa é composta por informações de 235 alunos. Desses, $55,32 \%$ são do sexo masculino. A faixa etária predominante é entre 19 e 24 anos $(64,68 \%)$, sendo que $74,04 \%$ dos alunos têm até 24 anos. Apenas 40,85\% desses alunos trabalham 40 horas semanais (ou mais). Em relação ao semestre letivo, $61,28 \%$ estão nos primeiros semestres do curso (até o $5^{\circ}$ ). Quanto ao número de disciplinas, a maioria cursa quatro ou mais disciplinas $(84,26 \%)$.

\subsection{Análise Descritiva dos Dados}

A Tabela 4 evidencia os resultados da análise descritiva dos dados.

\section{Tabela 4}

Estatística descritiva dos constructos da pesquisa

\begin{tabular}{|c|c|c|c|c|c|c|c|c|c|c|c|}
\hline C. & Ind. & Mín. & Máx. & Média & D.P. & C. & Ind. & Mín. & Máx. & Média & D.P. \\
\hline \multirow{12}{*}{$\begin{array}{l}0 \\
. \bar{U} \\
0 \\
0 \\
0 \\
0 \\
\frac{0}{n} \\
\frac{0}{0} \\
\overline{0} \\
. \overline{0} \\
\overline{0} \\
u\end{array}$} & $\mathrm{AEl}$ & 1,00 & 7,00 & 4,61 & 1,82 & \multirow{5}{*}{ 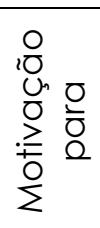 } & MPA 1 & 1,00 & 7,00 & 5,33 & 1,42 \\
\hline & AE2 & 1,00 & 7,00 & 4,68 & 1,71 & & MPA2 & 1,00 & 7,00 & 3,82 & 1,63 \\
\hline & AE3 & 1,00 & 7,00 & 5,17 & 1,56 & & MPA3 & 1,00 & 7,00 & 3,68 & 1,78 \\
\hline & ES1 & 1,00 & 7,00 & 5,10 & 1,60 & & MPA4 & 1,00 & 7,00 & 4,90 & 1,63 \\
\hline & ES2 & 1,00 & 7,00 & 4,56 & 1,67 & & MPA5 & 1,00 & 7,00 & 4,49 & 1,74 \\
\hline & ES3 & 1,00 & 7,00 & 5,04 & 1,43 & \multirow{7}{*}{ 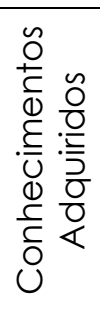 } & $\mathrm{CAl}$ & 1,00 & 7,00 & 4,93 & 1,55 \\
\hline & ES4 & 1,00 & 7,00 & 5,08 & 1,54 & & CA2 & 1,00 & 7,00 & 5,15 & 1,42 \\
\hline & OT1 & 1,00 & 7,00 & 4,87 & 1,61 & & CA3 & 1,00 & 7,00 & 4,83 & 1,66 \\
\hline & OT2 & 1,00 & 7,00 & 5,37 & 1,53 & & CA4 & 1,00 & 7,00 & 4,55 & 1,63 \\
\hline & REl & 1,00 & 7,00 & 5,28 & 1,54 & & CA5 & 1,00 & 7,00 & 4,50 & 1,68 \\
\hline & RE2 & 1,00 & 7,00 & 5,01 & 1,55 & & & & & & \\
\hline & RE3 & 1,00 & 7,00 & 5,29 & 1,50 & & CA6 & 1,00 & 7,00 & 4,94 & 1,61 \\
\hline
\end{tabular}

Legenda: C. Constructo; Ind. Indicador; Mín. Mínimo; Máx. Máximo; D.P. Desvio Padrão. AE. Autoeficácia; ES. Esperança; OT. Otimismo; RE. Resiliência.

Fonte: Dados da pesquisa. 
Em relação ao capital psicológico, observa-se que todos os indicadores pesquisados dos constructos de autoeficácia, esperança, otimismo e resiliência apresentaram respostas mínimas e máximas. Esses resultados revelam que nem todos os alunos desenvolveram seu capital psicológico. Bandura (1989) explica que as capacidades psicológicas cognitivas de um indivíduo sofrem influências de diferentes fatores, diferindo de pessoa a pessoa e há aqueles que não conseguem se desenvolver. Por essa razão, torna-se possível sugerir que esses indivíduos poderão ter dificuldades para se motivar a aprender ou para adquirir novos conhecimentos, de modo que possam posteriormente aplicá-los em suas atividades de trabalho.

Na dimensão de autoeficácia, o maior nível de concordância entre os participantes está relacionado ao indicador AE3, em que a maioria dos estudantes se sente segura quando apresenta informações de trabalho a um grupo de colegas. Em contrapartida, o maior nível de discordância (AEl) está relacionado à falta de segurança desses alunos quando representam sua área de trabalho em reuniões com gerentes superiores. Estes resultados sugerem que o curso de ciências contábeis pode desenvolver ações com vistas a minimizar esta insegurança.

O indicador ES1 apresentou o maior nível de concordância na dimensão esperança, o que revela que, quando a maioria dos alunos está com dificuldades no trabalho, pensam em muitas formas de resolvê-las. Já o indicador ES2, que indica se atualmente os alunos se veem em uma fase de sucesso no trabalho, apresentou o maior nível de discordância nas respostas. Esses resultados sugerem que os estudantes que possuem maior esperança, quando encontram uma dificuldade no trabalho tentam encontrar várias maneiras de solucionar o problema. Contudo, o maior nível de discordância encontrado nessa dimensão também sugere que nem todos os alunos acreditam estar em uma fase de sucesso no trabalho.

Na dimensão otimismo, a maior concordância foi no indicador OT2, o que indica que a maioria dos estudantes é otimista sobre o que acontecerá consigo no futuro em seu trabalho. Já o indicador com maior nível de discordância está relacionado a OT1, o que revela que nem todos os alunos visualizam o lado brilhante das coisas a respeito do seu trabalho. Tais achados indicam que a maioria dos estudantes entende que, em uma visão de futuro, poderá permanecer nesse trabalho. Também revelam que alguns alunos não estão satisfeitos com o seu trabalho.

O maior nível de concordância na dimensão resiliência está relacionado ao indicador RE3, que indica que a maioria dos estudantes afirma poder agir espontaneamente no ambiente de trabalho. Em contrapartida, o maior nível de discordância está no indicador RE2, que revela que nem todos os alunos acreditam poder superar as épocas difíceis no trabalho. Estes resultados sugerem que alguns estudantes acreditam que sairão fortalecidos depois de situações de adversidade. Porém, nem todos os estudantes acreditam conseguir superar as situações difíceis no trabalho. Uma possível explicação para esses resultados pode estar relacionada à baixa idade dos estudantes, às suas primeiras experiências no trabalho. 
Em relação à motivação para a aprendizagem, observou-se que o indicador que apresentou maior concordância foi o MPAl, que indica que a maioria dos alunos procura estudar o material disponibilizado da melhor maneira possível. Já o indicador que apresentou maior nível de discordância foi o MPA3, o que revela que investir em materiais do curso não é a primeira prioridade dos estudantes. Estes resultados evidenciam que a maioria dos alunos procuram dar o seu melhor para aprender com o material disponibilizado pelo professor

Quanto ao constructo de conhecimentos adquiridos, observa-se que há um grande nível de concordância no indicador CA2, que revela que, na percepção desses alunos, o curso de Ciências Contábeis aprimorou suas habilidades analíticas. Por sua vez, o indicador com maior discordância foi o CA5, que indica que o curso de Ciências Contábeis não melhorou as habilidades de comunicação. Pode-se inferir que os alunos acreditam que o curso impulsionou sua capacidade analítica, desenvolvendo seu modo de pensar em soluções práticas, mas proporcionou poucos momentos para aprimorar sua habilidade de comunicação.

\subsection{Validação dos Constructos de Mensuração}

Para realizar a validação dos constructos de mensuração, utilizou-se a análise fatorial confirmatória e a análise da validade discriminante. Na etapa da análise fatorial confirmatória, observou-se que todos os indicadores agruparam em seus respectivos constructos, validando a qualidade preditiva do modelo testado. Todos os indicadores alcançaram os padrões mínimos recomendados por Hair Jr. et al. (2009) para validação dos constructos, sendo todos mantidos no modelo de mensuração. Realizada a análise confirmatória, procedeu-se à análise discriminante. A Tabela 5 apresenta os indicadores de confiabilidade dos constructos.

\section{Tabela 5}

Indicadores de confiabilidade dos constructos de mensuração

\begin{tabular}{l|c|c|c}
\multicolumn{1}{c|}{ Constructos } & AC & CC & AVE \\
\hline Valores Mínimos Esperados => & $>0,70$ & $>0,50$ & $>0,50$ \\
\hline Capital Psicológico (CP) & 0,856 & 0,93 & 0,54 \\
\hline Motivação para Aprendizagem (MPA) & 0,836 & 0,82 & 0,50 \\
\hline Conhecimentos Adquiridos (CA) & 0,920 & 0,91 & 0,64 \\
\hline
\end{tabular}

Legenda: AC. Alfa de Cronbach; CC. Confiabilidade Composta; AVE. Variância Média Extraída.

Fonte: Dados da pesquisa.

Os valores das cargas padronizadas de cada constructo são superiores a 0,70, conforme recomendado por Hair Jr. et al. (2009). O mesmo se observa em relação à confiabilidade composta, que apresentou valores superiores a 0,80 para todos os constructos e a variância média extraída apresentou valores mínimos de 0,50. A Tabela 6 apresenta os resultados dos testes de análise da validade discriminante dos constructos. 
Tabela 6

Resultados dos testes de validade discriminante dos constructos de mensuração

Validade Discriminante pelo critério de Bagozzi e Philips (1982)

\begin{tabular}{cccccc}
\hline PAR & Constructo A & $\begin{array}{c}\text { Constrained } \\
(=1) \\
\text { Constructo }\end{array}$ & $\begin{array}{c}\text { Not } \\
\text { Qui-Quadrado } \\
\text { constrained } \\
\text { Qui- } \\
\text { Quadrado }\end{array}$ & $\begin{array}{c}\text { Diferença do } \\
\text { Qui-Quadrado }\end{array}$ & Sig. \\
\hline MPA & CP & 363,691 & 309,062 & 54,629 & 0,0000 \\
\hline CA & CP & 326,445 & 310,146 & 16,299 & 0,0001 \\
\hline CA & MPA & 205,815 & 197,717 & 8,098 & 0,0044 \\
\hline
\end{tabular}

Legenda: MPA. Motivação para Aprendizagem; CP. Capital Psicológico; CA. Conhecimentos Adquiridos.

Fonte: Dados da pesquisa.

Conforme Bagozzi e Philips (1982), para a análise do teste de validade discriminante de constructos, deve haver diferenças estatisticamente significativas entre os constructos, o que indicará que estes não medem o mesmo conceito. Esse teste consiste na análise das diferenças entre os constructos avaliados em um mesmo modelo estrutural, a partir do Qui ${ }^{2}$ dos modelos fixos e livres, efetuando-se a comparação da significância estatística das diferenças (Bagozzi \& Philips, 1982). Os resultados evidenciaram que todas as relações são estatisticamente significativas, o que revela que os constructos apresentam diferenças entre si. Dessa forma, torna-se possível realizar a modelagem estrutural para inferir sobre as relações objeto de estudo.

\subsection{Influência do Capital Psicológico na Motivação para Aprendizagem e Aquisição de Conhecimentos}

Os resultados do modelo estrutural testado são apresentados na Figura 2. 


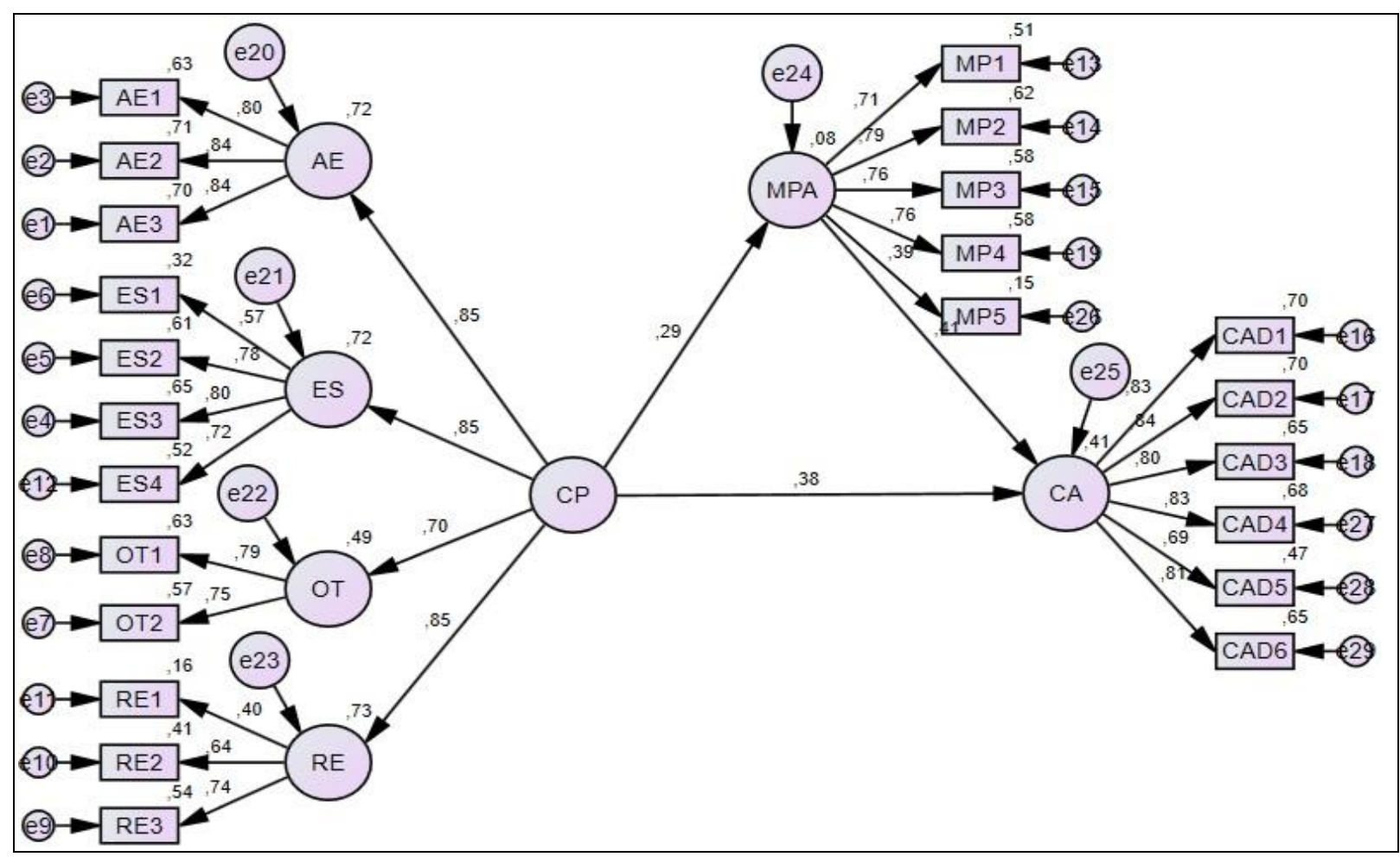

Figura 2 - Estimativas de caminhos do modelo de mensuração testado

CP. Capital Psicológico; AE. Autoeficácia; ES. Esperança; OT. Otimismo; RE. Resiliência; MPA. Motivação para Aprendizagem; CA. Conhecimentos Adquiridos. Índices de Ajuste: Qui² 555,025, p-value 0,000, Qui/GL 2,489, CFI 0,921, TLI 0,910, NFI 0,875, RMSEA 0,064.

Fonte: Dados da pesquisa.

Inicialmente, procurou-se identificar a influência direta do capital psicológico na motivação para aprendizagem $\left(\mathrm{H}_{1}\right)$. Os resultados encontrados revelaram que há uma relação positiva e significativa, entre o capital psicológico e a motivação para aprendizagem. Esses resultados revelam que alunos que possuem maior nível de capital psicológico são mais propensos a desenvolverem sua motivação para aprendizagem, resultados convergentes aos evidenciados por Pletsch e Zonatto (2018). Isso ocorre porque indivíduos que acreditam em suas capacidades, que possuem esperança e otimismo em alcançar os resultados e que se sentem seguros na sua área de trabalho são mais propensos a apresentarem motivação para estudar e aprender novos conhecimentos, pois por meio do estudo adquirirão os conhecimentos necessários para aplicar em seu trabalho.

Assim, o aluno que está mais motivado dedicará mais esforço aos estudos, irá procurar estudar o material disponibilizado pelos professores, dando o seu melhor. Isto ocorre quando este percebe a utilidade do ambiente de ensino, como adequado para promover a aprendizagem de conteúdos de seu interesse (Nunes \& Silveira, 2015). Essas evidências permitem aceitar a $\mathrm{H}_{1}$ "O capital psicológico influencia positivamente a motivação para aprendizagem".

A influência direta do capital psicológico na aquisição de conhecimentos indicou uma relação positiva e significativa, o que demonstra que os alunos com um maior nível de capital psicológico têm mais predisposição a adquirir conhecimentos, conforme constatado por Pletsch e Zonatto (2018). Nesses casos, indivíduos que desenvolveram suas crenças de autoeficácia, que são otimistas e resilientes, que estão sempre em busca de novos conhecimentos, acreditam que 
o curso de Ciências Contábeis desenvolveu suas habilidades de resolução de problemas e contribuiu para aprimorar as habilidades analíticas. Tais evidências permitem aceitar a $\mathrm{H}_{2}$ "O capital psicológico influencia positivamente $\mathrm{O}$ conhecimento adquirido".

A análise da influência mediadora da motivação para aprendizagem na relação entre capital psicológico e aquisição de conhecimentos, revelou que há uma relação direta e significativa entre a motivação para aprendizagem e a aquisição de conhecimentos. Tho (2017) e Pletsch e Zonatto (2018) também constataram relação positiva entre tais variáveis. Esses resultados revelam que a motivação para aprendizagem exerce influência na aquisição de conhecimentos, sendo capaz de mediar os efeitos do capital psicológico na aquisição de conhecimentos. Essas evidências permitem aceitar a $\mathrm{H}_{3}$ "a motivação para aprendizagem medeia positivamente a relação entre o capital psicológico e o conhecimento adquirido".

Em suma, os resultados encontrados indicam que, quando os estudantes apresentam maiores níveis de capital psicológico apresentam-se mais motivados para aprender. Nessa condição, desenvolvem um comportamento motivador para adquirir novos conhecimentos no ambiente de ensino. Por consequência, reconhecem as potenciais contribuições do curso de Ciências Contábeis para sua formação e atuação no trabalho.

A Tabela 7 apresenta uma síntese dos resultados das relações investigadas na pesquisa.

\section{Tabela 7}

Coeficientes padronizados e significâncias das relações do modelo testado na pesquisa

\begin{tabular}{c|c|c|c|c|c|c|c|c}
\hline \multicolumn{2}{c|}{$\begin{array}{c}\text { Caminhos } \\
\text { Estruturais }\end{array}$} & Estimates & $\begin{array}{c}\text { Erro } \\
\text { Padrão }\end{array}$ & $\mathbf{t}$ - values & $\boldsymbol{\rho}$ & $\begin{array}{c}\text { Coeficientes } \\
\text { Padronizados }\end{array}$ & $\mathbf{R}^{\mathbf{2}}$ \\
\hline MPA & $\leftarrow$ & CP & 0,345 & 0,082 & 4,218 & $* * *$ & 0,289 & 0,084 \\
\hline CA & $\leftarrow$ & CP & 0,583 & 0,099 & 5,918 & $* * *$ & 0,384 & 0,407 \\
\hline CA & $\leftarrow$ & MPA & 0,523 & 0,074 & 7,051 & $* * *$ & 0,410 & 0 \\
\hline
\end{tabular}

Legenda: CP. Capital Psicológico; MPA. Motivação para Aprendizagem; CA. Conhecimentos Adquiridos.

Fonte: Dados da pesquisa.

A análise dos índices de ajustes do modelo testado indica que este apresenta parâmetros adequados, o que permite a realização das inferências apresentadas sobre as relações teóricas investigadas na pesquisa. A fim de verificar se variáveis pessoais e contextuais podem explicar eventuais diferenças na amostra analisada, procedeu-se a uma análise adicional, cujos resultados são apresentados na Tabela 8. 


\section{Tabela 8}

Resultados da análise adicional

\begin{tabular}{|c|c|c|c|c|c|c|c|c|c|}
\hline & \multicolumn{2}{|c|}{ Variáveis Dependentes $\rightarrow$} & $\mathrm{AE}$ & ES & OT & RE & $C P$ & MPA & CA \\
\hline \multirow{5}{*}{ 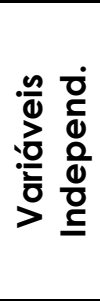 } & Faixa Etária & \multirow{5}{*}{ 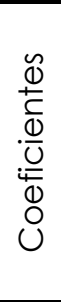 } & 0,068 & 0,040 & 0,072 & 0,104 & 0,085 & $0,157^{*}$ & $-0,061$ \\
\hline & Sexo & & 0,094 & 0,057 & $-0,046$ & 0,098 & 0,071 & $-0,133^{*}$ & $-0,072$ \\
\hline & Semestre Letivo & & 0,106 & 0,064 & 0,032 & 0,087 & 0,093 & $-0,159 *$ & 0,064 \\
\hline & $\begin{array}{l}\text { Quantidade de } \\
\text { Disciplinas }\end{array}$ & & $-0,058$ & $-0,108$ & $-0,075$ & $-0,127^{* *}$ & $-0,116$ & 0,113 & $0,122^{*}$ \\
\hline & $\begin{array}{l}\text { Carga Horária de } \\
\text { Trabalho }\end{array}$ & & $0,130^{* *}$ & 0,041 & $-0,001$ & $-0,023$ & 0,053 & $-0,015$ & 0,106 \\
\hline $\mathbf{R}^{\mathbf{2}}$ & & & 0,067 & 0,030 & 0,015 & 0,053 & 0,054 & 0,049 & 0,036 \\
\hline Sig. & ova & & 0,000 & 0,000 & 0,000 & 0,000 & 0,000 & 0,000 & 0,000 \\
\hline
\end{tabular}

Legenda: AE. Autoeficácia; ES. Esperança; OT. Otimismo; RE. Resiliência; CP. Capital Psicológico; MPA. Motivação para Aprendizagem; CA. Conhecimentos Adquiridos.

* Significância ao nível de 5\%. ** Significância ao nível de $10 \%$.

Fonte: Dados da pesquisa.

Conforme os resultados da Tabela 8 , as crenças de autoeficácia apresentam relação positiva e significativa com a carga horária de trabalho semanal dos estudantes. Esses resultados revelam que alunos que trabalham em uma jornada de trabalho superior tornam-se mais propensos a desenvolverem sua capacidade psicológica de autoeficácia, comparativamente àqueles alunos que trabalham até 20 horas semanais. Nesses casos, esses alunos são mais propensos a mobilizar recursos cognitivos para empreender esforços e definir o curso de ação para obter êxito na execução de suas tarefas de trabalho (Luthans et al., 2007; Siqueira, 2014).

Contudo, alunos que cursam mais disciplinas tornam-se menos propensos a desenvolverem a capacidade psicológica de resiliência para o trabalho. Uma possível explicação para este achado é que os indivíduos que possuem menor dedicação ao trabalho, podem apresentar dificuldade de se portar frente a situações desafiadoras e difíceis no trabalho. Nesse caso, os estudantes podem acreditar que não serão capazes de desenvolver suas atribuições de trabalho, alcançar os resultados esperados e se manter nessa atividade ou profissão. Esses elementos contribuirão para com a decisão da troca de emprego (Siqueira, 2014) ou de curso, aumentando os níveis de evasão universitária.

Os resultados de Poots e Cassidy (2020) revelaram que a idade e a escolaridade da mãe foram preditores significativos do capital psicológico dos acadêmicos analisados e representam desta forma, a variação do capital psicológico. Tais resultados divergem dos achados desta pesquisa, visto que a quantidade de disciplinas e a carga horária de trabalho semanal foram os fatores relevantes para explicar as diferenças do capital psicológico na amostra analisada.

As evidências encontradas revelam ainda que estudantes mais velhos são mais propensos a apresentarem um comportamento motivador para aprendizagem. Essas evidências indicam que o amadurecimento pessoal e profissional é uma variável condicionante ao comportamento motivador dos estudantes que trabalham e cursam sua graduação em Ciências Contábeis. Estudantes do sexo feminino e que estão entre o início e o meio do curso também são os que apresentam maior comportamento motivador para aprendizagem. 
Esses resultados reforçam as evidências, encontradas na literatura, de que alunos que trabalham se motivam para aprender de maneira distinta (Tho, 2017; Pletsch \& Zonatto 2018). Revelam ainda, que alunos que estão no início do curso são mais suscetíveis a mobilizarem recursos psicológicos positivos, os quais refletem em motivação para explorar da melhor forma as condições disponibilizadas no ambiente de ensino para promover sua aprendizagem.

No entanto, em fases finais do curso, a mobilização de recursos cognitivos para aprender é reduzida. Uma possível explicação para esses resultados pode estar relacionada ao ambiente de trabalho, às atividades já desenvolvidas e conhecidas pelos estudantes e à apropriação de conhecimentos adequados ao desenvolvimento de suas atividades atuais de trabalho. Nesse caso, a falta de perspectivas ou de novas oportunidades pode refletir no comportamento e nas crenças de que o estudante já possui conhecimentos suficientes para atuar na sua profissão ou na área de atuação escolhida para trabalhar. Essa explicação é convergente à reflexão proposta por Nunes e Silveira (2015), para compreender a aprendizagem em ambiente universitário.

Há que se considerar ainda as condições para aprendizagem no ambiente de ensino, as quais também podem influenciar essa relação. A eventual sobreposição de conteúdos abordados nas disciplinas ou a abordagem de conteúdos recorrentes, com os quais o aluno já teve contato e aprendeu, e a falta de entusiasmo do professor em demonstrar a relevância dos conteúdos para a formação do contador ou sua relação com as atividades práticas do trabalho, também podem ser fatores capazes de explicar o menor interesse dos estudantes para se motivarem a aprender.

Por fim, observa-se que a quantidade de disciplinas cursadas apresenta relação positiva e significativa com a aquisição de conhecimentos. Esses resultados revelam que alunos que estão mais envolvidos com o curso tornam-se mais propensos a adquirirem novos conhecimentos e apresentarem um comportamento motivado para aprender. Em contrapartida, esses achados sugerem que a realização de poucas disciplinas pode ser um fator que venha comprometer a atratividade do curso ao aluno e causar a desistência do curso ou da profissão.

\subsection{Discussão dos Resultados}

Esta pesquisa teve como objetivo testar o modelo proposto, conforme a Figura 1. Os resultados apoiaram amplamente este modelo, pois revelaram que o capital psicológico auxilia para com a melhora da motivação para aprendizagem e facilita a aquisição de conhecimentos, visto que influenciou positivamente a motivação para aprendizagem e a aquisição de conhecimentos. Tais resultados corroboram com os achados de Pletsch e Zonatto (2018). Estes achados acrescentam também a pesquisas anteriores de Riolli et al. (2012), pois os autores relataram que estudantes com altos níveis de capital psicológico serão mais capazes de lidar com o estresse acadêmico, mantendo assim, o bem-estar físico e psicológico, o que refletiu positivamente nesta pesquisa na motivação para aprender e na aquisição de conhecimentos.

Portanto, "personalidades mais otimistas tendem a ver os aspectos positivos associados a novas demandas. Da mesma forma, a esperança está associada à 
saliência dos objetivos pessoais e à confiança de que o cumprimento dos objetivos permitirá melhorar a vida de alguém" (Riolli et al., 2012, p. 1203). Ainda, a crença de autoeficácia, conforme Bandura (1986) está relacionada a uma ampla gama de situações, como lidar com situações difíceis, estresse, hábitos, bem como, motivação para estabelecer e atingir metas. Deste modo, juntas, estas capacidades psicológicas sugerem que os acadêmicos que possuem altos níveis de capital psicológico resistem mais facilmente as dificuldades do âmbito acadêmico, pois sentem-se motivados a aprender e adquirir novos conhecimentos. Contudo, na visão de Venkatesh e Blaskovich (2012), diferentes estados mentais têm diferentes efeitos sobre o comportamento dos indivíduos.

No caso desta pesquisa, o capital psicológico se concentrou no desenvolvimento das forças positivas dos indivíduos, visto seus impactos positivos no modelo proposto. Tais argumentos reforçam as constatações de Luthans et al. (2007) de que as quatro capacidades psicológicas juntas resultam em melhor desempenho e atitudes positivas pelos indivíduos no ambiente em que estão inseridas. You (2016, p. 17) também evidenciou os benefícios do capital psicológico no âmbito acadêmico, pois identificou que o capital psicológico estava relacionado positivamente com o empoderamento da aprendizagem, sendo "reconhecido como um recurso importante para o comportamento e a eficácia organizacional".

Além disso, confirmou-se o efeito mediador da motivação para aprendizagem na relação entre o capital psicológico e a aquisição de conhecimentos, pois a motivação relacionou-se positivamente com a aquisição de conhecimentos. Assim, apoiando os achados de Nguyen e Nguyen (2010), Tho (2017) e Pletsch e Zonatto (2018), pois também constataram os efeitos positivos da motivação na aquisição de conhecimentos. Nesse sentido, destaca-se que a motivação para o aprendizado moldará a direção, o foco e até mesmo o nível de esforço empregado pelos acadêmicos nas suas atividades de aprendizado (Cole et al., 2004), sendo a motivação para aprendizagem importante na vida dos estudantes para continuar seus estudos na universidade (Hamjah et al., 2011).

Na visão de Wong-On-Wing et al. (2010), os indivíduos se sentem motivados com vistas a alcançarem algum objetivo. O papel mediador da motivação para aprendizagem no contexto acadêmico também foi verificado em pesquisas (Tho, 2017; Pletsch \& Zonatto, 2018). Contudo, Tho (2017) não analisou os efeitos do capital psicológico nas relações propostas neste estudo. Nesse sentido, as conclusões deste estudo confirmam o poder explicativo do capital psicológico em ambientes educacionais, incentivando pesquisas adicionais sobre os efeitos do capital psicológico em atitudes e comportamentos de estudantes.

Diante destes resultados, o desafio não é apenas encontrar fontes criativas de talentos, mas sim, encontrar formas inovadoras de capitalizar e desenvolver as capacidades humanas, sociais e psicológicas, visto que tais recursos humanos são capazes de sustentar a vantagem competitiva nas organizações (Luthans et al., 2007) e no ambiente acadêmico. Sugerem-se alguns exemplos de como a motivação para aprender pode ser aprimorada, conforme a visão de Cole et al. (2004), visto que esta variável potencializa o desenvolvimento do capital psicológico e a aquisição de novos conhecimentos dos indivíduos.

Os educadores (corpo docente) podem aumentar a motivação para aprender enfatizando a importância e a aplicabilidade do material, visando 
conectar o material discutido em sala de aula aos motivos intrínsecos dos alunos (Cole et al., 2004). Para os calouros, as IES podem oferecer oportunidades de aprender mais sobre assuntos do seu interesse utilizando auto avaliações, com vistas a ajudá-los a encontrar campos de estudos que atendam aos seus interesses (Cole et al., 2004). Estas sugestões propostas por Cole et al. (2004) podem auxiliar a criar condições suscetíveis de incentivar sentimentos de motivação para o aprendizado, pois de acordo com Blumenfeld et al. (2006), a motivação para o aprendizado aprimora o conhecimento e as habilidades adquiridas pelos acadêmicos, pois alunos com elevada motivação para aprender utilizarão estratégias mais eficazes para a aprendizagem e terão maiores níveis de comprometimento com a aquisição de novos conhecimentos e habilidades.

Pesquisas constataram que a motivação para aprendizagem dos alunos é um dos fatores principais que contribuem para com a eficácia do resultado da aprendizagem (Diseth et al., 2010; Nguyen \& Nguyen, 2010). Assim, para criar e sustentar uma vantagem competitiva, os conhecimentos e a experiência dos indivíduos podem ser vistos como um recurso estratégico (Bender \& Fish, 2000) e suscetível de ser melhorado por meio do capital psicológico positivo. Deste modo, assim como o desempenho bem-sucedido de qualquer tarefa depende da capacidade, motivação e oportunidade, a aquisição e a transferência de conhecimentos podem ser explicadas, e até mesmo depende de três fatores principais: habilidade, motivação e oportunidades (Chang et al., 2012). Logo, o capital psicológico pode potencializar tais fatores e melhorar a motivação para aprendizagem e a aquisição de conhecimentos dos acadêmicos.

Para tanto, o capital psicológico e a motivação para aprendizagem devem ser levados em consideração na prática educacional das IES e em pesquisas futuras sobre os antecedentes da aquisição de conhecimentos. Assim, este estudo pode fornecer conhecimento sobre os preditores da aquisição de novos conhecimentos, resultados estes que podem orientar alunos, professores e coordenadores de curso nos esforços para desenvolver e aprimorar o aprendizado e o desempenho acadêmico.

\section{CONSIDERAÇÕES FINAIS E IMPLICAÇÕES}

Reconhecendo que o capital psicológico dos indivíduos pode servir como um fator capaz de potencializar a motivação para aprendizagem e a aquisição de conhecimentos, esta pesquisa buscou comprovar tais relações e os efeitos mediadores da motivação na relação entre o capital psicológico e a aquisição de conhecimentos. Tais relacionamentos foram comprovados com a realização da pesquisa, possibilitando o alcance do objetivo proposto. Portanto, o presente estudo fornece evidências de que o modelo proposto pode ser mediado positivamente pela motivação para aprendizagem e pode ser aplicado de maneira útil para a realização de intervenções na IES analisada e, por sua vez, melhorar o ambiente acadêmico.

Os resultados contribuem para o avanço dos conhecimentos existentes sobre o tema, fornecendo novas evidências de fatores cognitivos, comportamentais e contextuais que podem influenciar a relação existente entre o capital psicológico, a motivação para aprendizagem e a aquisição de 
conhecimentos. Da mesma forma, chamam a atenção para a necessidade de se investigar variáveis demográficas e contextuais que podem explicar eventuais diferenças entre os estudantes pesquisados, em face de aspectos pessoais, das condições de ensino ou da dedicação dos alunos ao ensino e/ou às atividades de trabalho.

Uma vez que indivíduos diferem em suas capacidades cognitivas (Bandura, 1986; Luthans et al., 2007), tais aspectos podem explicar reações distintas dos alunos frente aos estímulos do ambiente, o que permite melhor compreender os fatores de influência da ação e do comportamento humano para aprendizagem (Pletsch \& Zonatto, 2018). Apesar da motivação ser fator fundamental para a aprendizagem, há que se considerar que os indivíduos possuem um sistema cognitivo autorreferente que lhes permite realizar julgamentos e decidir sobre 0 que é importante ou não para si (Bandura, 1986). Essas avaliações, racionais ou não, refletirão em suas escolhas e na definição de seu comportamento, razão pela qual também poderão refletir de algum modo nos níveis de aprendizagem dos estudantes (Tho, 2017; Pletsch \& Zonatto, 2018).

Esta pesquisa apresenta implicações para a pesquisa, o poder do capital psicológico e da motivação para aprendizagem para efetivar resultados psicológicos positivos nos acadêmicos e implicações para a IES, educadores e coordenadores no desenvolvimento e promoção de resultados positivos com base nesse valioso capital humano. No que tange a pesquisa, este estudo aborda novas evidências sobre o capital psicológico, lançando luz sobre seus efeitos no ambiente acadêmico, mais precisamente sobre atitudes e comportamentos dos indivíduos, como é o caso da motivação para aprendizagem e aquisição de conhecimentos, elementos que foram pouco explorados em pesquisas anteriores.

Diante de uma perspectiva teórica, o estudo identifica dois fatores que o capital psicológico potencializa e fornece evidências empíricas do papel da motivação na relação entre capital psicológico e aquisição de conhecimentos. Deste modo, a motivação para o aprendizado não auxilia apenas os acadêmicos a aprimorar seu nível de conhecimentos adquiridos na IES, mas também os ajuda a desenvolver capacidades psicológicas positivas. Para tanto, tais capacidades ao estarem presentes nos alunos, facilitam a aquisição de conhecimentos e aumentam a motivação para aprender.

Em termos de implicações práticas, as conclusões desta pesquisa sinalizam as partes participantes, incluindo a IES, para reconhecer o papel do capital psicológico no contexto acadêmico, pois os resultados sugerem que os acadêmicos do curso de Ciências Contábeis são capazes de desenvolver as quatro capacidades do capital psicológico (autoeficácia, esperança, otimismo e resiliência) e estas auxiliarão a melhorar a motivação para aprender e a aquisição de novos conhecimentos. Os reflexos de tais atitudes pelos educadores das IES (desenvolvimento do capital psicológico e motivação) farão com que o conhecimento adquirido por esses acadêmicos seja aplicado diretamente as tarefas diárias e nas organizações empresariais em que atuam. Tais resultados beneficiam o curso, a IES e as empresas nas quais os acadêmicos trabalham.

Conforme Riolli et al. (2012, p. 1206), "as implicações para os educadores universitários incluem um foco em aspectos do capital psicológico dentro do currículo acadêmico", pois "o capital psicológico pode ser tão ou mais valioso como recurso para os estudantes do que o conteúdo acadêmico tradicional, pois 
o capital psicológico ajuda os alunos a perseverar em seus estudos de maneira psicológica e fisicamente mais saudável". Sugere-se que os educadores e coordenadores passam a planejar e implementar programas que desenvolvem as capacidades positivas do capital psicológico, a fim de ajudá-los a se sentirem mais motivados e a adquirir novos conhecimentos que podem ser aplicados posteriormente as organizações. Tais iniciativas "pode ajudar os alunos menos psicologicamente resilientes" (Riolli et al., 2012, p. 1206).

Portanto, o conhecimento que os acadêmicos adquirem nas IES desempenha um papel importante no processo de ensino-aprendizagem. Contudo, a relevância e a utilidade do conhecimento adquirido pelos acadêmicos, depende da sua motivação para aprender, bem como, da sua autoeficácia, esperança, otimismo e resiliência quando estão nas IES. Além destas implicações, dada a crescente pressão de uma economia global, as organizações podem também buscar explorar os benefícios do capital psicológico (Venkatesh \& Blaskovich, 2012).

Embora este estudo possui contribuições, utilizou uma amostra intencional, medidas de autorrelato, alunos de um curso de graduação presencial, abordagem apenas quantitativa, limitações estas que devem ser reconhecidas. Outra limitação está relacionada as variáveis utilizadas, visto que a adição de outras variáveis pode apresentar novas evidências sobre o tema.

Como recomendações a estudos futuros, sugere-se a aplicação desta pesquisa em outras amostras de alunos de IES, localizadas em outras regiões do país e de outras modalidades de ensino, além do presencial. Sugere-se também a aplicação deste estudo a outros profissionais. Análises comparativas entre universidades públicas e privadas, também podem revelar aspectos similares ou distintos do ambiente de ensino que podem interferir na relação entre o capital psicológico, a motivação para aprendizagem e a aquisição de conhecimentos.

Outras variáveis foram preteridas nesta pesquisa, o que pode ser observado quando da realização de novos estudos. Aspectos cognitivos, como a resiliência para aprendizagem e a capacidade de absorção de novos conhecimentos ou elementos motivacionais, como os diferentes estilos de aprendizagem de alunos, também são variáveis que podem auxiliar na compreensão dos antecedentes à aquisição de conhecimentos. Variáveis consequentes à aquisição de conhecimentos, como a capacidade dos indivíduos para transferir novos conhecimentos ou os fatores que favorecem e/ou dificultam tal ação, também se constituem oportunidades para novos estudos. Adicionalmente, destaca-se que é necessária a observância de variáveis contextuais que podem auxiliar no entendimento de potenciais diferenças na amostra analisada, conforme proposto também por Poots e Cassidy (2020).

\section{REFERÊNCIAS}

Baldvinsdottir, G., Mitchell, F., \& Norreklit, H. (2010). Issues in the relationship between theory and practice in management accounting. Management Accounting Research, 21 (2), 79-82. https://doi.org/10.1016/j.mar.2010.02.006 
Bandura, A. (1986). Social foundations of thought and action: A social cognitive theory. Englewood Cliffs, New Jersey: Prentice-Hall.

Bandura, A. (1989). Human agency in social cognitive theory. American Psychologist, 44 (9), 1175-1 184. https://doi.org/10.1037/0003-066X.44.9.1175

Bandura, A. (2008). A evolução da teoria social cognitiva. In: Bandura, A., Azzi, R. G., \& Polydoro, S. Teoria social cognitiva: conceitos básicos. Porto Alegre: Artmed.

Bagozzi, R. P., \& Phillips, L. W. (1982). Representing and testing organizational theories: A holistic construal. Administrative Science Quarterly, 27, 459-489. $10.2307 / 2392322$

Bender, S., \& Fish, A. (2000). The transfer of knowledge and the retention of expertise: the continuing need for global assignments. Journal of Knowledge Management, 4(2), 125-137. https://doi.org/10.1 108/13673270010372251

Birnberg, J. G., Luft, J., \& Shields, M. D. (2007). Psychology theory in management accounting research. In. Chapman, C. S., Hopwood, A. G., \& Shields, M. D. Handbook of Management Accounting Research, 1(4), 113-135. https://doi.org/10.1016/S1751-3243(06)01004-2

Blumenfeld, P. C., Kempler, T. M., \& Krajcik, J. S. (2006). Chapter 28: motivation and cognitive engagement in learning environment. In Sawyer, R. K. (Ed.). The Cambridge Handbook of the Learning Sciences, Cambridge University Press, Cambridge, 475-488.

Chang, Y.-Y., Gong, Y., \& Peng, M. W. (2012). Expatriate knowledge transfer, subsidiary absorptive capacity and subsidiary performance. Academy of Management Journal, 55(4), 927-948. https://doi.org/10.5465/amj.2010.0985

Cohen, W. M., \& Levinthal, D. A. (1990). Absorptive capacity: A new perspective on learning and innovation. Administrative Science Quarterly, 35(1), 128-152. $10.2307 / 2393553$

Cole, M. S., Field, H. S., \& Harris, S. G. (2004). Student learning motivation and psychological hardiness: Interactive effects on students' reactions to a management class. Academy of Management Learning and Education, 3(1), 64-85. https://doi.org/10.5465/amle.2004.12436819

Comin, F. S., Inocente, D. F., \& Miura, I. K. (2011). Aprendizagem organizacional e gestão do conhecimento: Pautas para a gestão de pessoas. Revista Brasileira de Orientação Profissional, 12(2), 227-239.

Diseth, A., Pallesen, S., Brunborg, G. S., \& Larsen, S. (2010). Academic achievement among first semester undergraduate psychology students: the role of course experience, effort, motives and learning strategies. Higher Education, 59(3), 335-352. 10.1007/s10734-009-9251-8 
Ersanlı, C. Y. (2015). The relationship between students' academic self-efficacy and language learning motivation: A study of 8th graders. Procedia-Social and Behavioral Sciences, 199, 472-478. 10.1016/j.sbspro.2015.07.534

Hair Jr., J. F., Babin, B. J., Money, A. H., \& Samovel, P. (2009). Análise multivariada de dados. 6. ed. Porto Alegre: Bookman.

Hamjah, S. H., Ismail, Z., Rasit, R. M., \& Rozali, E. A. (2011). Methods of increasing learning motivation among students. Procedia-Social and Behavioral Sciences, 18, 138-147. 10.1016/j.sbspro.2011.05.021

Luthans, F., Luthans, K. W., \& Luthans, B. C. (2004). Positive psychological capital: Beyond human and social capital. Business Horizons, 47(1), 45-50. 10.1016/j.bushor.2003.11.007

Luthans, F., Youssef, C. M., \& Avolio, B. J. (2007). Psychological Capital: Developing the Human Competitive Edge. New York: Oxford University Press, 2007.

Luthans, F., Youssef, C. M., \& Avolio, B. J. (2015). Psychological capital and beyond. Oxford University, Press: New York.

Nguyen, T. T. M., \& Nguyen, T. D. (2010). Determinants of learning performance of business students in a transitional Market. Quality Assurance in Education, 18(4), 304-31 6. https://doi.org/10.1108/09684881011079152

Nunes, A. I. B., \& Silveira, R. N. (2015). Psicologia da aprendizagem. 3. ed. Ceará: EdUECE.

Pan, P., \& Perera, H. (2012). Market relevance of university accounting programs: Evidence from Australia. Accounting Forum, 36(2), 91-108. https://doi.org/10.1016/j.accfor.2011.11.001

Pletsch, C. S., \& Zonatto, V. C. da S. (2018). Evidence of the effects of psychological capital on the transfer of knowledge from accounting students to business organizations. Journal of Knowledge Management, 22(8), 1826-1843. https://doi.org/10.1108/JKM-04-2018-0270

Poots, A., \& Cassidy, T. (2020). Academic expectation, self-compassion, psychological capital, social support and student wellbeing. International Journal of Educational Research, 99, 1-9. https://doi.org/10.1016/j.ijer.2019.101506

Riolli, L., Savicki, V., \& Richards, J. (2012). Psychological capital as a buffer to student stress. Psychology, 3(12), 1202-1207.

Siqueira, M. M. M. (2014). Novas medidas do comportamento organizacional: ferramentas de diagnóstico e de gestão. Porto Alegre: Artmed.

Venkatesh, R., \& Blaskovich, J. (2012). The mediating effect of psychological capital on the budget participation-job performance relationship. Journal of 
Management Accounting Research, 24(1), 159-175. https://doi.org/10.2308/jmar-50202

Tamer, C. M. V. S., Viana, C. C., Soares, L. A. C. F., \& Lima, M. S. (2013). Perfil do profissional contábil demandado pelo mercado de trabalho: um estudo no norte do Brasil. Revista Universo Contábil, 9(3), 143-162. 10.4270/RUC.2013326

Tho, N. D. (2017). Knowledge transfer from business schools to business organizations: the roles absorptive capacity, learning motivation, acquired knowledge and job autonomy. Journal of Knowledge Management, 21 (5), 1240-1253. https://doi.org/10.1 108/JKM-08-2016-0349

Thompson, K. R., Lemmon, G., \& Walter, T. J. (2015). Employee engagement and positive psychological capital. Organizational Dynamics, 44(3), 185-195. 10.1016/j.orgdyn.2015.05.004

Wong-On-Wing, B., Guo, L., \& Lui, G. (2010). Intrinsic and extrinsic motivation and participation in budgeting: Antecedents and consequences. Behavioral Research in Accounting, 22 (2), 133-153. 10.2308/bria.2010.22.2.133

You, J. W. (2016). The relationship among college students' psychological capital, learning empowerment, and engagement. Learning and Individual Differences, 49, 17-24. https://doi.org/10.1016/j.lindif.2016.05.001

Zonatto, V. C. S., Silva, A., \& Gonçalves, M. (2018). Influência da motivação para o trabalho no comprometimento organizacional. Revista de Administração IMED, 8(1), 169-190. https://doi.org/10.18256/2237-7956.2018.v8i1.2180

Zonatto, V. C. da S., Weber, A., \& Nascimento, J. C. (2019). Efeitos da participação orçamentária na assimetria informacional, estresse ocupacional e desempenho gerencial. Revista de Administração Contemporânea, 23(1), 6791. https://doi.org/10.1590/1982-7849rac2019170327 
CONTRIBUIÇÕES DOS AUTORES

\begin{tabular}{|l|c|c|c|c|c|}
\hline \multicolumn{1}{|c|}{ Contribuição } & $\begin{array}{c}\text { Vinícius } \\
\text { Costa da } \\
\text { Silva Zonatto }\end{array}$ & $\begin{array}{c}\text { Júlia } \\
\text { Ziliotto } \\
\text { Zanotto }\end{array}$ & $\begin{array}{c}\text { Priscila } \\
\text { Rodrigues } \\
\text { da Silva }\end{array}$ & $\begin{array}{c}\text { Larissa } \\
\text { Degenhart }\end{array}$ & $\begin{array}{c}\text { Luiz } \\
\text { Fenrique } \\
\text { Marquezan }\end{array}$ \\
\hline $\begin{array}{l}\text { 1. Idealização e concepção do } \\
\text { assunto e tema da pesquisa }\end{array}$ & $\checkmark$ & $\checkmark$ & $\checkmark$ & $\checkmark$ & \\
\hline $\begin{array}{l}\text { 2. Definição do problema de } \\
\text { pesquisa }\end{array}$ & $\checkmark$ & $\checkmark$ & $\checkmark$ & $\checkmark$ & \\
\hline $\begin{array}{l}\text { 3. Desenvolvimento da } \\
\text { Plataforma Teórica }\end{array}$ & $\checkmark$ & $\checkmark$ & & $\checkmark$ & \\
\hline $\begin{array}{l}\text { 4. Delineamento da } \\
\text { abordagem metodológica da } \\
\text { pesquisa }\end{array}$ & $\checkmark$ & $\checkmark$ & $\checkmark$ & & \\
\hline 5. Coleta de dados & $\checkmark$ & $\checkmark$ & & $\checkmark$ & \\
\hline $\begin{array}{l}\text { 6. Análises e interpretações dos } \\
\text { dados coletados }\end{array}$ & $\checkmark$ & $\checkmark$ & & & \\
\hline 7. Conclusões da pesquisa & $\checkmark$ & $\checkmark$ & $\checkmark$ & $\checkmark$ & $\checkmark$ \\
\hline $\begin{array}{l}\text { 8. Revisão crítica do manuscrito } \\
\text { 9. Redação final do manuscrito, } \\
\text { conforme as normas } \\
\text { estabelecidas pela Revista. }\end{array}$ & & & & & $\checkmark$ \\
\hline 10. Orientação & $\checkmark$ & & & $\checkmark$ \\
\hline
\end{tabular}




\section{ANEXO I - INSTRUMENTO DE PESQUISA}

\section{Bloco 1: Dados para Caracterização da Amostra da Pesquisa}

1) Faixa Etária: ( ) Até 18 anos ( ) 19 a 24 anos ( ) 25 a 30 anos ( ) 31 a 35 anos ( ) Mais de 35 anos

2) Sexo: ( ) Feminino ( ) Masculino

3) Semestre que está no Curso em Ciências Contábeis:

4) Informe a quantidade de disciplinas que está cursando este semestre:

5) Trabalho em: ( ) Escritório de Contabilidade ( ) Empresa Privada ( ) Setor Público

( ) Terceiro Setor ( ) Outro. Especificar

( ) No momento não estou trabalhando.

6) Caso você trabalhe, informe a Carga Horária de sua jornada de trabalho semanal:

( ) até 12 horas ( ) entre 13 a 20 horas ( ) entre 21 a 30 horas ( ) entre 31 e 39 horas ( ) 40 horas

7) Já possui alguma outra graduação ou curso técnico?

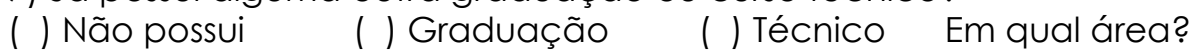

\section{Bloco 2: Questões de Pesquisa}

Por gentileza, indicar à medida que você concorda ou discorda com as assertivas apresentadas a seguir. Considere a escala variando de 1 (fortemente em desacordo) até 7 (concordo fortemente).

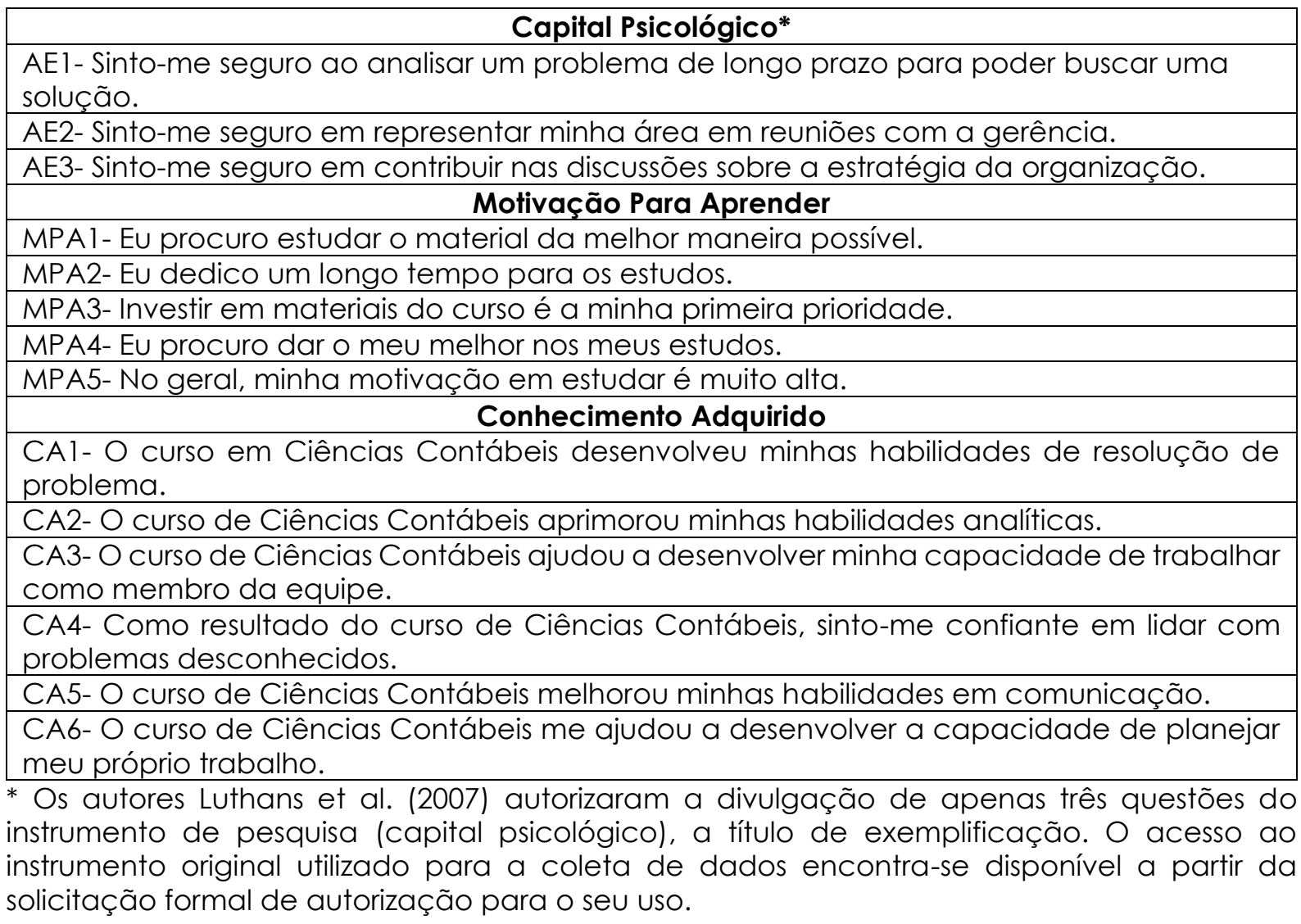




\section{ANEXO II - TERMO DE CONSENTIMENTO LIVRE E ESCLARECIDO INFORMADO}

\begin{tabular}{|c|c|}
\hline $\begin{array}{l}\text { 1. Identificação do Projeto de Pesquisa } \\
\text { Título do Projeto: Influência do capital } \\
\text { aquisição de conhecimentos }\end{array}$ & ológico na motivação para aprendizagem e \\
\hline $\begin{array}{l}\text { Objetivo do Projeto: Analisar a influêl } \\
\text { aprendizagem e aquisição de conhe } \\
\text { presencial em Ciências Contábeis. }\end{array}$ & $\begin{array}{l}\text { do capital psicológico na motivação para } \\
\text { entos de alunos de um curso de graduação }\end{array}$ \\
\hline $\begin{array}{l}\text { Área do Conhecimento: Ciências Con } \\
\text { Comportamental) }\end{array}$ & eis (abordagem relacionada a Contabilidade \\
\hline Curso: Ciências Contábeis & \\
\hline Número de Participantes no Curso: 410 & $\begin{array}{l}\text { Número total de participantes: _ _ (total de } \\
\text { voluntários) }\end{array}$ \\
\hline Patrocinador da Pesquisa: Pesquisa real & a com financiamento próprio. \\
\hline $\begin{array}{l}\text { Instituição onde será realizada: } \\
\text { Universidade) }\end{array}$ & laos estudantes foi informada o nome da \\
\hline Nome dos pesquisadores e colaborad & (aos estudantes foi informado o nome \\
\hline
\end{tabular}

Você está sendo convidado(a) a participar voluntariamente do projeto de pesquisa intitulado "Influência do capital psicológico na motivação para aprendizagem e aquisição de conhecimentos". Este documento contém todas as informações necessárias sobre a pesquisa que está sendo realizada. Sua colaboração neste estudo será de muita importância para nós. Sendo assim, consideramos importante prestarmos alguns esclarecimentos antes de convidá-lo a participar da pesquisa, respondendo aos questionamentos que the são apresentados, se assim desejar.

Esclarecimentos:

A pesquisa aplicada é regida pelos princípios gerais relativos:

(i) ao consentimento informado;

(ii) a preocupação em não prejudicar a entidade e as pessoas que nela trabalham; e, nosso compromisso em

(iii) manter a confidencialidade das pessoas e da entidade.

Assim, os seguintes procedimentos foram adotados para assegurar a confidencialidade dos participantes da pesquisa e da entidade estudada:

a) O respondente participará da pesquisa voluntariamente, se assim desejar;

b) O respondente terá liberdade de desistir ou de interromper a colaboração nesta pesquisa no momento em que desejar, sem necessidade de qualquer explicação;

c) O questionário aplicado não solicitará nenhuma identificação individual pessoal do estudante:

d) Apenas os pesquisadores envolvidos terão acesso aos questionários respondidos;

e) Ao preencher voluntariamente e entregar o instrumento de coleta de dados, o respondente concorda que sejam divulgados os resultados da pesquisa em publicações científicas; e,

f) Qualquer dúvida referente ao questionário pode ser esclarecida neste ou a qualquer momento com os pesquisadores responsáveis pela execução da pesquisa realizada.

Informações sobre as questões apresentadas no formulário de coleta de dados:

Todas as questões apresentadas no anexo (instrumento de coleta de dados) são objetivas, de múltipla escolha, em que você informará, se assim desejar, seu nível de discordância ou concordância com as afirmativas apresentadas. Assim, recomendados que leia atentamente todas as questões antes de respondê-las, de modo que tenhas uma visão geral da pesquisa e possa decidir se deseja ou não participar do projeto, apresentando voluntariamente sua resposta.

$\Rightarrow$ Recomendamos que antes de prosseguir, leia atentamente as questões de pesquisa em anexo.

Declaração de ciência e aceite em participar da pesquisa: 
Recebidas tais informações, se você desejar voluntariamente participar de nossa pesquisa, respondendo aos questionamentos apresentados, você declara:

a) concordar com os termos da pesquisa realizada;

b) ter recebido todas as explicações e orientações necessárias ao esclarecimento de suas eventuais dúvidas particulares (se houverem);

c) estar ciente de que poderia ter deixado de participar do trabalho a qualquer momento; e,

d) que os dados coletados sejam tratados de maneira consolidada e utilizados na produção e divulgação de trabalhos acadêmicos.

Local e Data (informações apresentadas aos estudantes)

Prof. Dr. $x x x x x x x x x x x x x x x x x x x x x x x x x x x x x$ Assinatura do Participante da Pesquisa (opcional)

Professor Responsável pelo Projeto de Pesquisa 